\title{
Reproductive tract infection-Lessons learned from the field: Where do we go from here?
}

Jennifer Grant

Diana Measham

Follow this and additional works at: https://knowledgecommons.popcouncil.org/departments_sbsr-rh

Part of the Demography, Population, and Ecology Commons, Family, Life Course, and Society Commons, and the International Public Health Commons How does access to this work benefit you? Let us know!

\section{Recommended Citation}

Grant, Jennifer and Diana Measham. 1996. "Reproductive tract infection-Lessons learned from the field: Where do we go from here?" Robert $\mathrm{H}$. Ebert Program on Critical Issues in Reproductive Health Publication Series. New York: Population Council. 


\section{Reproductive Tract Infection}

\section{Lessons Learned from the Field:}

\section{Where do we go from here?}

Report of a seminar presented under the auspices of the Population Council's Robert H. Ebert Program on Critical Issues

in Reproductive Health and Population

February 6-7, 1995

New York, New York

Editorial Assistance

Jennifer Grant, M.A.

Diana M. Measham, MSc. 
The Population Council

The Robert H. Ebert Program on Critical Issues

in Reproductive Health and Population

One Dag Hammarskjold Plaza

New York, NY 10017 USA

Telephone (212) 339-0500

Fax (212) 755-6052

Published March 1996

Cover and text printed on recycled paper in the USA 


\section{ACKNOWLEDGMENTS}

We are grateful to the Ford Foundation for generous support of the seminar and production of this publication, and to the Rockefeller Foundation for support of the seminar. In addition, some seminar participants were supported with USAID and SIDA funds. We also thank Virginia Kallianes for assistance in preparing this document. 


\section{ABBREVIATIONS}

$\begin{array}{ll}\text { AIDS } & \text { Acquired immune deficiency syndrome } \\ \text { ELISA } & \text { Enzyme-linked immunoassay } \\ \text { GC } & \text { Gonococcus (organism that causes Gonorrhea) } \\ \text { KOH } & \text { Potassium hydroxide } \\ \text { HIV } & \text { Human immunodeficiency virus } \\ \text { IUD } & \text { Intrauterine device } \\ \text { LCR } & \text { Ligase chain reaction } \\ \text { LED } & \text { Leukocyte esterase dipstick } \\ \text { PCR } & \text { Polymerase chain reaction } \\ \text { PID } & \text { Pelvic inflammatory disease } \\ \text { RPR } & \text { Rapid plasma reagin } \\ \text { RTI } & \text { Reproductive tract infection } \\ \text { STD } & \text { Sexually transmitted disease } \\ \text { TPHA } & \text { Treponema pallidum (syphilis) hemagglutination assay (for antibodies) } \\ \text { VDRL } & \text { Venereal Disease Research Laboratory }\end{array}$




\section{TABLE OF CONTENTS}

EXECUTIVE SUMMARY

INTRODUCTION AND OVERVIEW

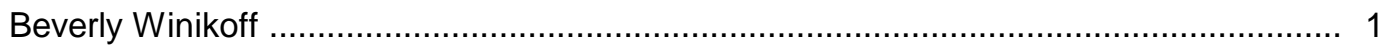

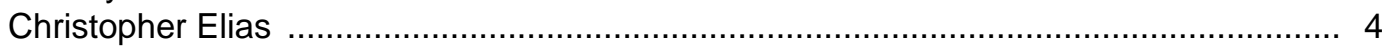

UPDATE ON STD DIAGNOSIS

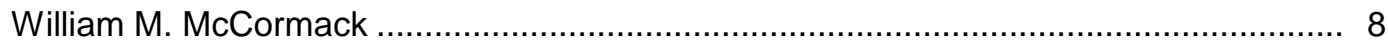

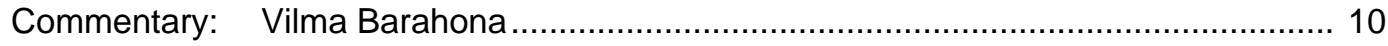

DEFINING THE SCOPE OF RTIS: QUANTITATIVE RESEARCH

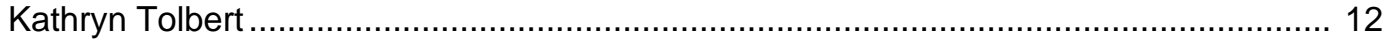

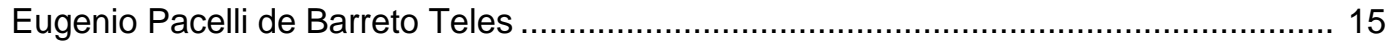

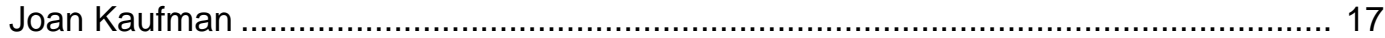

INDIVIDUAL PERCEPTIONS: QUALITATIVE RTI RESEARCH

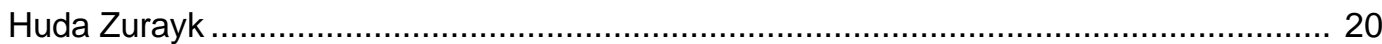

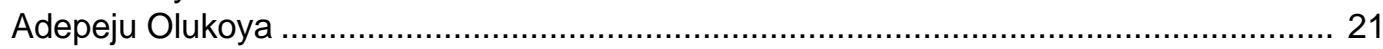

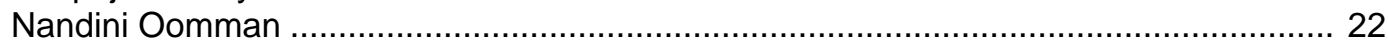

THE UTILITY OF ALGORITHMS AND RISK SCREENING

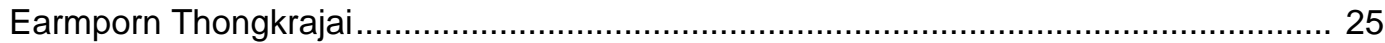

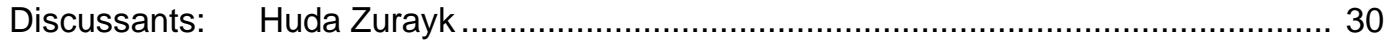

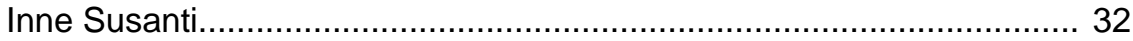

BUILDING THE COALITIONS NEEDED TO ADDRESS RTIS:

SERVICE PROVIDERS, POLICYMAKERS, COMMUNITIES

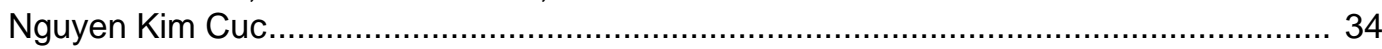

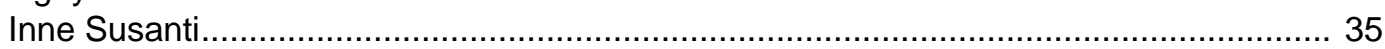

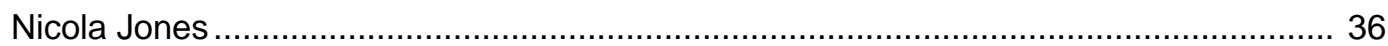

IMPACT ASSESSMENT: WHAT CRITERIA DO WE USE TO DEMONSTRATE THE IMPORTANCE OF RTIS TO POLICYMAKERS?

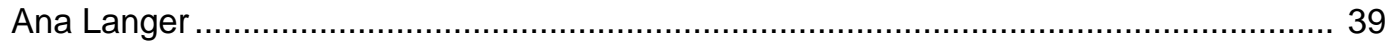

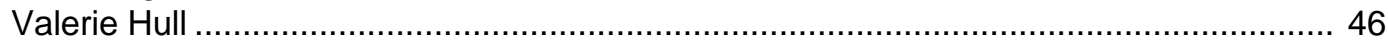

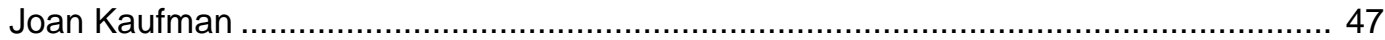

LESSONS LEARNED FROM RESEARCH ON RTIS:

SUMMARIZING THE OBSTACLES ENCOUNTERED

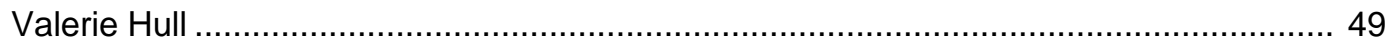

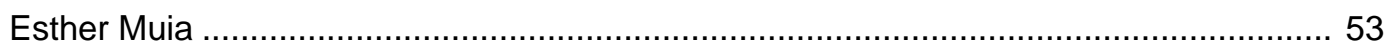

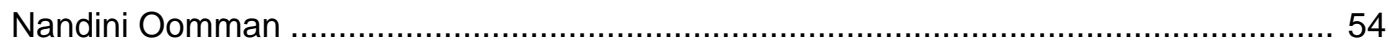

DEFINING THE RANGE OF FUTURE RESEARCH PRIORITIES AND

INTERVENTIONS

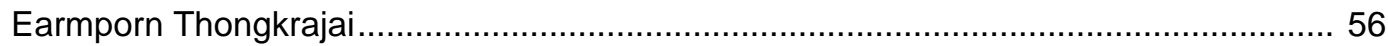

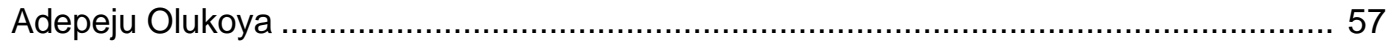

CLOSING SUMMARY

Beverly Winikoff and Christopher Elias ……….................................................... 58

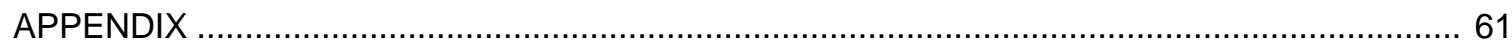

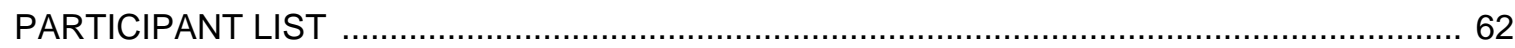





\section{EXECUTIVE SUMMARY}

\section{Introduction and Overview}

Interest in Reproductive tract infections (RTIs) has increased enormously, and enthusiasm to act is palpable. A great deal of work must be done, however, before we will be in a position to respond adequately to the problem. As a result, the Population Council convened a meeting to examine how best to use available tools and information, learn about potential service delivery approaches, and examine the direction of research. The meeting began with an examination of what is known about the prevalence, distribution, determinants, characteristics, and consequences of RTIs, as well as the common elements of an intervention framework. The group then moved on to examine and discuss a range of key topics, as summarized below.

There are five basic approaches to diagnosing RTIs. These were discussed in terms of their utility for diagnosing chlamydia, gonorrhea, genital ulcers, syphilis, herpes, chancroid, human papilloma virus (HPV), trichomoniasis, candidiasis, and bacterial vaginosis (BV).

Quantitative research conducted in Mexico, Brazil, and China was presented. The Mexico study, for example, found higher levels of RTIs than expected among women in both hospital and community samples. Chlamydia rates among women in the hospital sample were found to be as high as those found in a study of commercial sex workers in Mexico.

Qualitative research conducted in Egypt (Giza), Nigeria (Lagos), and India (Rajasthan) was presented. The Rajasthan study, for example, focused on dhola Pani, the local term for white discharge, in an effort to develop an ethnomedical model of this problem. Among other things, women believe that poverty leads to physiological weakness, which in turn results in discharge. Because they view the root cause of the problem as an economic one, they do not seek health care.

Research on the utility of algorithms and risk screening in Khon Kaen province, Thailand and Giza, Egypt was presented. In both cases, the risk factors investigated were found not to correspond with clinical data, and, therefore, not to be predictive for RTIs. In Giza, for example, a number of methods were used to determine the extent to which reports or observations of symptoms, compared to medical examinations, could provide an estimate of RTI prevalence. It was found that the presence of discharge-regardless of who reported it and whether or not it was considered medically suspicious - was not predictive for RTIs.

Information presented on Vietnam and Bali, Indonesia made it clear that there is an urgent need to develop multi-sectoral, interdisciplinary coalitions to overcome the obstacles to effective RTI management. There are, however, many obstacles to effective coalition building. In order to overcome some of these obstacles, the Ford Foundation in the Philippines is supporting programs to bring activists from a wide range of backgrounds together to work on RTIs.

In spite of increasing consensus regarding the importance of addressing sexually transmitted (STDs) and merging vertical programs and services, numerous questions arise when it comes to investing resources in this area. Is it really necessary? Are STD programs costeffective? Can the impact of STD-related activities be measured? Is it feasible to implement all the services necessary to ensure that an STD program is effective? Each of these questions was addressed based on the outcomes of related research, which, it was noted, has yet to provide sufficient information to overcome the skepticism. There is an urgent need to conduct further research and to provide the skeptics with clear and precise information on the direct and indirect 
consequences of RTIs, and to illustrate the possibilities for integrating RTI interventions with existing programs.

General obstacles related to work in the area of RTIs include lack of awareness of the problem and the limited power of women in society. Obstacles to developing research include difficulties in setting local priorities due to lack of dialogue with or input from the community and a lack of alliances between researchers and service providers. Proposals for overcoming some of these obstacles were presented, as were the specific obstacles confronted by RTI research conducted in Rajasthan, India and Kenya.

Priorities for future research and programming included: further research on the scope and consequences of RTIs; integration of RTI services with other types of health care; continued investment in female-controlled technology; research on gender and power relations and their relationship to STDs and related protective measures; and research on appropriate low-cost diagnostics and screening tools.

There was broad agreement among participants that candida, BV, and trichomonas are the most widespread infections. These infections are relatively easy to deal with, but are not the most serious. This poses a difficult question: what does one do when the infections that are easiest to treat pose the least serious health problems? There was also broad agreement that providers must be able to diagnose and treat RTIs in order to provide contraceptive services of an acceptable quality.

The group heard a great deal about the complex issues surrounding RTIs. While more questions were raised than conclusions reached, the meeting helped to facilitate a move forward in dealing with this serious public health problem. 


\section{INTRODUCTION AND OVERVIEW}

\section{Beverly Winikoff}

The Population Council

New York, New York

As the title of this meeting implies, we did not gather to discuss a finished product, but neither are we just beginning to look at the issues surrounding reproductive tract infections (RTIs). These issues are so complex that we did not want to wait for the all of the research that is underway to be completed prior to examining the direction of our work in this area. The timing of this meeting is particularly apt: interest in RTIs is becoming widespread and enthusiasm to do something about the problem —and to do something soon-is palpable. There is, however, much more work to be done before we will know how to respond adequately to the problem.

From its inception, the Population Council's Robert H. Ebert Program on Critical Issues in Reproductive Health and Population has been interested in the subject of RTIs and sexually transmitted diseases (STDs). The Program was established in 1988 to bring attention to serious and understudied - and often controversial-issues affecting reproductive health. The subject of RTIs is clearly relevant to the program's mandate for several reasons, including the following:

The problem is enormous The World Health Organization (WHO) estimates that 100 million acts of intercourse take place daily and that these result in the transmission of an estimated 356,000 sexually transmitted infections per day.

The problem is poorly defined Until recently, there has been very little qualitative or quantitative research on the extent and dimensions of the problem.

The problem relates to the provision of contraceptive services It is highly relevant to the Population Council and other sister institutions working in the field of family planning and reproductive health.

The problem is controversial Concerns aroused by discussions of RTIs, and especially of STDs, are emblematic of gender and power inequities, subjects which generate controversy.

At the same time, and more urgently, a number of different forces have focused interest on RTIs. Several well-publicized studies have demonstrated that levels of infections are alarmingly high, surprising both women's health advocates and the public health community. The increased focus on quality of care in family planning also brought attention to RTIs, reminding us of issues surrounding a health care provider's ability to diagnose infections in family planning clients, appropriate use of IUDs, and the risk to a client of iatrogenic infections. The fact that STDs are a known co-factor in AIDS transmission has also focused attention on the topic. Finally, over 
the months since the International Conference on Population and Development (ICPD) held in Cairo in September 1995, there has been accelerating interest in the idea of reproductive health.

Nonetheless, while there is strong impetus to develop strategies to deal with RTIs, there are great obstacles to doing so. Related services are expensive and difficult to provide. They require a range of diagnostic tests and equipment, specific and complicated training, and drugs that may not normally be available in a clinic setting. In addition, clinics would have to deal with the complex issues of partner identification, notification, and treatment. We also lack the technical tools for treatment, screening, and diagnosis of RTIs in resource-constrained environments. A further impediment to addressing RTIs is that these services are currently orphan services. Providers fear that existing services will be stigmatized if RTI treatment is offered alongside family planning services, for example, because RTIs are associated with STDs, even when they are not sexually transmitted. An increased focus on RTIs can also be threatening to providers of IUDs and hormonal contraceptives that do not protect against sexually transmitted infections (oral contraceptives, NORPLANT ${ }^{\circledR}$ implants, Depo Provera). The most significant obstacle to addressing RTIs is the implied social critique that accompanies the issue of RTIs and the gender power questions this problem raises. Such questions, some of which are noted below, may threaten traditional political and social structures.

Should men shoulder the blame for women's health?

Is it fair-or is now the time - to examine traditional male behavior and make normative judgements or propose change?

Is there a need to make men do things they might not otherwise choose to do, including using condoms?

The issue of RTIs raises questions regarding widely-held assumptions about sexuality. Not surprisingly, talking about sexual encounters makes people uncomfortable. The data available indicate, however, that often, sexual encounters are not voluntary, pleasurable, or safe for women, who may lack control over the number of partners they have, the timing of sexual activity, men's behavior, and contraceptive use. Confronting the problem of RTIs requires facing these troubling issues.

Despite the difficulties outlined above, we have begun to study RTIs in both quantitative and qualitative ways, as the agenda of this meeting indicates. We have tried to determine if it is important to quantify the extent of the problem, and, if so, among which groups? The general population? Particular regions? We have also examined the utility of community and individual perceptions gathered through qualitative research. Whose perceptions are we interested in? 
Women's? Men's? Special groups'? Special regions'? How can we best use the information gathered through both qualitative and quantitative research? For program planning? For political ends? For advocacy? To improve research?

We are also looking very carefully at various prevention strategies. While we have some guideposts, we do not yet have a clear road map on this issue. There are numerous areas that demand further exploration, including: the role of information, education, and counseling; quality of care and provider practices; the extent to which condom promotion is a realistic prevention strategy; and the extent to which women's empowerment-including access to resources, legal rights, and their ability to make choices and participate equally in the nature of and decisionmaking regarding their relationships with men—can be seen as a prevention strategy. We also need to examine treatment as a prevention strategy, in that it protects the individual and the community and may prevent other diseases, such as AIDS. We face a major dilemma in this area, and must determine who should be treated, and when they should receive treatment. We must also examine community and individual definitions of illness, and the role of these definitions in the development of prevention and treatment strategies.

There are a few things that we can say with confidence. We know that there exists widespread incidence of RTls and that the specific patterns of these infections vary: some are STDs, some are not; and some are more serious than others. We know that we disagree on the infections that merit the most focus, and why. There is also a lack of understanding among women about the etiology, seriousness, and range of infections. In addition, clinicians lack an understanding of the problem and do not have the ability to provide appropriate information or detect cases. Finally, we know that we have little or no information on program approaches and that we are unable to give clear advice to policymakers and program managers.

As we convene this gathering to discuss this complicated issue, we hope to: examine how to use the tools and information available from quantitative and qualitative research in both advocacy and program planning; learn about the approaches to service delivery that may be most fruitful; and examine whether we should change our direction and/or the type of the research we are conducting on this topic.

In some ways, this meeting is part of an ongoing internal discussion. The agenda focuses on a number of collaborative projects in which the Council has participated, although others will also be discussed. We hope that by sharing our results and thinking to date we will help others who also struggle with these issues, and we are sure that your contributions will help 
us immeasurably as we move forward with our own work on RTls.

\section{Christopher Elias}

The Population Council

Bangkok, Thailand

While there are many unanswered questions regarding reproductive tract infections (RTIs), interest in the issue has increased and our thinking has evolved considerably over the last several years. A broad outline of issues related to RTIs, which I hope will help start our discussions, is outlined below. The remainder of the meeting will shed further light on these issues and give us an opportunity to discuss their implications for programs.

\section{Definitions}

There are three types of RTIs:

1. Sexually transmitted diseases (STDs).

2. Endogenous infections: infections, such as bacterial vaginosis and candidiasis, caused by overgrowth of microorganisms normally present in the vagina.

3. latrogenic infections: infections associated with medical procedures, such as unsafe abortion, IUD insertion, and labor and delivery practices.

As this list indicates, RTIs have different determinants. They also have different consequences. As a result, they require different intervention strategies.

\section{Prevalence studies}

Prevalence studies have found that RTIs are extremely common and that prevalence rates are extremely variable. There is no readily discernible pattern of prevalence to help us determine which women are most in need of services. These studies have highlighted a number of problems, including the fact that many infections are asymptomatic. In addition, perceptions of symptoms do not correspond well with recognizable clinical syndromes as defined by biomedical paradigms. That is, a woman in a village may have a name or a way of describing her illness that may or may not have very much to do with its clinical name, for example gonorrhea, chlamydia, or syphilis. We have also learned that clinical and lab results vary tremendously in terms of their diagnostic utility, revealing differences in diagnostic criteria as well as clinical acumen. 


\section{Consequences of RTIs}

RTIs have a broad range of consequences for both women and children. Women face possible infertility, ectopic pregnancy, chronic pelvic pain, and a higher risk of HIV infection; and infants exposed to congenital infections (gonorrhea, chlamydia, syphilis, herpes simplex) may develop serious problems.

RTIs also have an impact on family planning programs. By compromising fertility, pregnancy outcome, and child survival, they may decrease the demand for contraception. If RTIs are seen as possible side effects of contraceptives, women may not use them. In addition, there are real and perceived associations between RTIs and particular contraceptive methods that may result in client or provider bias against these methods. Finally, while many infections are asymptomatic, women often come to family planning clinics with complaints related to RTIs when they are symptomatic. If providers are unprepared to deal with the complaint that prompted the visit, because they are not trained to do so or do not have the necessary equipment or supplies, it diminishes their credibility with the women they serve, in addition to jeopardizing the health of women who do, in fact, have infections.

\section{Determinants of RTls}

The following framework, which was developed by Judith Wasserheit and Ward Cates, helps us to understand the range of factors that affect RTI patterns.

Microbiological determinants influence an individual's likelihood of having an RTI. Changes in vaginal flora, and the existence of other RTIs, may be important. Hormonal factors (including cervical ectopy and mucous), seminal fluid, and changes in the immune system (related to pregnancy or HIV, for example) also influence an individual's susceptibility to infections.

Personal environments also affect the likelihood of infections with certain organisms. A woman's sexual behavior-including her number of sexual partners, age of coital debut, participation in commercial sex, and whether her partner has intercourse with commercial sex workers-can make her more susceptible. Her health behavior-including use of condom/ barrier methods, oral contraceptives, IUDs, intravaginal preparations, and vaginal douches-also influences her susceptibility. Circumcision also affects individuals' risk of infection. While the effect of male circumcision is protective, particularly for viral infections such as HIV and chancroid, some researchers have raised the concern that female circumcision may increase the risk of some infections. Finally, whether and how infected individuals seek help when they feel that they have an infection is also an influential factor. 
Macro-environmental factors-including socio-economic, political, demographic, geographic, and technological factors-also influence the transmission, identification, and treatment of infections.

\section{Framework for intervention strategies}

Designing and implementing appropriate services will require the coordination of diverse inputs, including personnel, financial resources, and service structures, the availability and pattern of which are highly variable. There are, however, common elements for an intervention framework, as outlined below.

Primary prevention of infections Strategies to prevent STDs include delaying coital debut, reducing the number of sexual partners, and promoting condoms; preventing endogenous infections by improving knowledge of physiology and hygiene, and encouraging appropriate use of antibiotics; and preventing iatrogenic infections by improving the quality of abortions, IUD insertion, and childbirth practices.

Identification and/or treatment of established infections While many women are asymptomatic, many of those with symptoms do seek help from service providers. Standardizing case management is very important, but in doing so, we should think critically about the riskassessment component of some of the algorithms being recommended. We also need to screen for asymptomatic infections. Diagnostic tests for RTIs tend to be expensive and would have to be rationed, but we could use selective case finding for high-risk populations. We need to move beyond the question of "Do we notify partners?" to determining how to do so in a culturally sensitive way. Mass or epidemiological treatment has also been suggested as an intervention strategy, but it requires evaluation, the latter of which must include an evaluation of the costs of emerging antibiotic resistance in a community.

Minimizing the complications of infection This approach is costly, but also has a potentially high yield. Its stakes are also higher, insofar as it implies dealing with infections that exist and are progressing or have progressed to a later, more critical phase. Specifically, we can work to improve:

the management of septic abortions;

early identification and treatment of pregnant women with syphilis;

alarm and transport mechanisms for the management of ectopic pregnancy; infertility management; and 
cervical cancer screening and management.

The above provides a broad overview of the issues surrounding RTIs, which we will discuss in more detail as the meeting progresses. 
William M. McCormack

\section{UPDATE ON STD DIAGNOSIS}

State University of New York

Health Science Center

Brooklyn, New York

There are five basic approaches to diagnosing infection:

1. visualizing the organism directly;

2. using antibody tests that measure the body's response to the organism;

3. growing the organism using a culture preparation;

4. searching for antigens using non-amplified techniques; and

5. searching for antigens using amplification.

Specific organisms can be diagnosed by using more than one of the approaches listed above. Chlamydia and Human papilloma virus (HPV) are the most complex infections to diagnose. A summary of the ways to diagnose various reproductive tract infections (RTIs) is provided below.

\section{Chlamydia}

Chlamydia can be visualized, but no one uses this method of diagnosis. Similarly, there is no value to using an antibody test. Currently, the "gold standard" for diagnosing chlamydia is to use a culture preparation. This, however, is expensive and complicated. DNA probes have been available for about a decade and while they are probably about 80 percent as sensitive as culture preparations, they are about 99 percent specific ${ }^{1}$. Amplified antigen detection tests are about 1520 percent more sensitive and specific than culture techniques. These new amplified antigen detection tests, such as polymerase chain reaction (PCR) and ligase chain reaction (LCR), can pick up antigens in urine, which is important from a public health perspective in that it implies that screening can be conducted in a wide variety of locations. While these tests currently cost about US\$20 each, they will be cheaper in volume.

\section{Gonorrhea}

A gram stain is a very good diagnostic test for gonorrhea in men. For both men and women, with or without symptoms, culture is an excellent diagnostic test if an incubator,

Ninety-nine percent specificity is an important clinical concept. It means that if you test 100 women who are negative, 99 of them will have negative test results, or, if you test 100 women who are negative, 1 will test positive. 
technician, and other necessary supplies are available. While there is not, given the above, a compelling reason for developing non-culture tests, industry has developed them, and they are marketed in tandem with chlamydia tests.

\section{Genital ulcers}

In most parts of the world, genital ulcers are the result of syphilis, herpes, and/or chancroid. Tests to diagnose these illnesses in the ulcer phase are only available on a limited basis and are imperfect, at best.

\section{Syphilis}

There is a dark-field test for primary syphilis, but it requires a dark-field microscope and technician, both of which are very expensive. Direct fluorescent antibody staining is possible, but also requires a microscope and technician. No antigen detection tests are on the market. In all stages, syphilis is usually diagnosed by serologic tests.

\section{Herpes}

The herpes virus can be visualized using a "Tzanck prep," which involves staining for the strange-looking cells that it induces. This is an insensitive test, however, and not widely used. Culture is the "gold standard" for diagnosis of herpes lesions, but is expensive and requires a lab. Antigen detection tests are available, but are less sensitive than culture.

\section{Chancroid}

It is possible to look for chancroid organisms using a gram stain, but this is insensitive and not widely used. No useful blood test exists. Chancroid can be grown, but this requires special media and labs. Antigen detection techniques are not yet available.

\section{Human papilloma virus (HPV)}

We are currently in the initial stages of understanding the HPV organism. It cannot be visualized directly. You can look for changes in cells, but there is no blood test available and the organism cannot be grown in culture. It can be categorized on the basis of DNA probes. Other diagnostic tests are under development that will improve on the DNA probes.

We should not be making HPV treatment decisions based on the results of inadequate or inaccurate diagnostic tests. The treatment options available are not only ineffective, but also potentially harmful. Currently, HPV management relies on Pap smears. Diagnosing HPV 
requires looking for changes brought on by the organism instead of the organism itself. Patients who have abnormal Pap smears, most of which are due to HPV infection, should be referred to a gynecologist.

\section{Trichomoniasis}

Trichomonas vaginalis can be visualized in direct wet preparations. No useful blood test exists. The organism can be cultured and cultures add 10-15 percent to the yield over wet preparations, particularly in asymptomatic individuals. There are no marketed antigen detection tests for trichomoniasis, but they are under development.

\section{Candidiasis}

Candida organisms can be seen in wet preparations or in gram stains of vaginal material. Sensitivity, however, is only 60 percent when this approach is used. No useful blood test exists. Candida organisms can be grown in culture, which is the "gold standard" for their diagnosis. Antigen detection tests have been developed for candida, but none of those that are presently on the market are useful for the diagnosis of vulvo-vaginal candidiasis.

\section{Bacterial vaginosis}

Bacterial vaginosis is the absence of normal vaginal flora or the replacement of normal vaginal flora with abnormal vaginal flora. Clinical diagnosis involves measuring vaginal $\mathrm{pH}$, detecting abnormal odor after alkalinizing the secretions, and noting whether the secretions are abnormal in appearance. This approach requires a microscope, but could be used in any area of the world. There has been interest in developing antigen detection tests.

\section{Vilma Barahona}

\section{COMMENTARY}

Hospital General Aurelio Valdivieso

Department of Clinical Pathology

Oaxaca, Mexico

Reproductive tract infections (RTIs) are extremely common and can have serious consequences for the health and social well-being of women in developing countries. They are, however, preventable, and can be treated. Because Pap smears are relatively cheap in the developing world, they are a useful means of screening for reproductive morbidity. Risk for or presence of 
RTIs should be taken into account in the development and delivery of all services related to family planning, safe motherhood, and AIDS prevention.

In addition, research on RTIs must take into account the conditions in which women live and the economic, political, cultural, and social context that defines the relationships between women and men. In Mexico, for instance, as poverty becomes more widespread, an increasing number of men from rural areas migrate to the north and to the U.S. in search of work, and more women are forced to trade sex for money in order to survive. These problems increase the prevalence of RTIs, as well as AIDS.

Like most of my colleagues, I read journals and attend international conferences. Upon returning home, however, I am faced with the reality of old and obsolete machines, a lack of office and laboratory equipment, a scarcity of well-trained technicians, and many other constraints. I am forced to identify other means to carry out my work within these constraints, which is a difficult and tiring task.

In summary, when considering advances in technology and research, we also need to consider ways to facilitate technology transfer at a reasonable cost. We must keep in mind that the transfer of new information and technology is not automatic, and is often hampered by socioeconomic conditions. 


\title{
DEFINING THE SCOPE OF RTIS: QUANTITATIVE RESEARCH
}

\author{
Kathryn Tolbert \\ The Population Council \\ Mexico City, Mexico
}

\section{Introduction}

The work I will report on represents an ambitious first project for the Health Research Center of Comitán. For the Population Council, it has served as a pilot study for a larger, comparative study of reproductive tract infections (RTIs) in two other states in Mexico. Ultimately, we will have data from three states on the prevalence of RTIs, and on aspects of sexual behavior which may relate to the presence of infections.

\section{Quantitative study}

The clinical research was conducted at the Comitán general hospital and laboratory. Both the general medicine outpatient clinic (GMC) and the gynecology clinic (GC) contributed patients for screening. A total of 416 women seeking a range of services from the two clinics were studied. Enrollment was undertaken through clinical census. To be enrolled, women needed to be over 15 years of age and attending one of the clinics. Pregnant women were not excluded, but the data collected on these women were analyzed separately. An additional 93 women who had participated in community development projects in four periurban communities around Comitán were also studied, as were 108 women from a nearby collective farming community (ejido). These women represented a convenience sample, and were enrolled by invitation. The study was explained to the women and they were told they would be given a physical exam and Pap smear, informed of the results, and, if an infection was detected, be treated. Their consent was obtained and noted.

\section{Methodology}

A short questionnaire was administered to gather demographic, health, and risk information. The women were also given a pelvic exam and Pap smear. Samples were taken and the results of the physical exam were noted on each patient's record. Diagnostic tests were performed for the following:

Syphilis, by VDRL test

Gonorrhea, by immediate microscopic exam and culture

Trichomoniasis, by immediate microscopic exam

Chlamydia trachomatis, by ELISA test on endocervical brushings and cell culture 
Moniliasis, by immediate microscopic exam

Bacterial vaginosis (a syndrome of profuse vaginal discharge with a characteristic odor, a pH of less than 5, and large numbers of white cells and "clue cells"), by microscopic examination

Because of budget limitations, only a subsample of each group was tested for chlamydia.

$\underline{\text { Results }}$

There were no significant differences among the women from the two clinics in terms of age, schooling, civil status, age of menarche, age at first pregnancy, or number of living children. There were, however, differences in pregnancy status: 51 percent of the women attending the GMC were pregnant, compared to 15 percent of those attending the GC (see Table 1).

\begin{tabular}{|c|c|c|c|c|c|c|c|}
\hline & & Com & án Gener & $\begin{array}{l}\text { able } 1 \\
\text { Hospita }\end{array}$ & opulation & & \\
\hline Clinic & $\begin{array}{c}\text { Mean } \\
\text { age }\end{array}$ & $\begin{array}{l}\text { School } \\
\text { (none or }\end{array}$ & & & $\begin{array}{l}\text { Average } \\
\text { age at }\end{array}$ & $\begin{array}{c}\text { Average } \\
\text { number of }\end{array}$ & Pregnant \\
\hline & & & Married & In union & & & \\
\hline $\begin{array}{l}\text { GMC } \\
(n=250)\end{array}$ & 30 & $73 \%$ & $66 \%$ & $29 \%$ & 18.6 & 3.1 & $51 \%$ \\
\hline $\begin{array}{l}G C \\
(n=166)\end{array}$ & 33 & $75 \%$ & $63 \%$ & $28 \%$ & 18.8 & 3.5 & $15 \%$ \\
\hline
\end{tabular}

The women who attended the clinics came almost exclusively for reproductive health problems. They complained of pain, menstrual difficulties, postpartum difficulties, pregnancyrelated concerns, and symptoms that might indicate the presence of RTIs, such as burning, itching, ulcers, "bumps," and lesions in their lower reproductive tract.

The levels of RTIs found in the sample of 416 women who attended the Comitán General Hospital clinics were higher than expected, with more than 50 percent of women testing positive for one or more pathogens. Of particular interest was the fact that 12.4 percent of the subsample of 145 women tested for chlamydia were found to have the infection. This is the same level of prevalence as that found in a sample of commercial sex workers in Chiapas (Tapachula) by a Health Secretariat study. Both gonorrhea and syphilis rates are low (there were no cases of 
syphilis), perhaps representing the ready availability of antibiotics (over-the-counter without prescription) and their frequent use for respiratory and intestinal infections.

Specific infection rates are reported separately for pregnant and non-pregnant women.

The pregnant women were slightly more educated than the non-pregnant women, with 63 percent reporting no schooling or incomplete primary education. This is probably due to the fact that the non-pregnant group includes the older women in the study, who probably have less education than the younger women due to advances in extending education to women in the last two decades. No other socio-demographic variable was significantly different for pregnant women. Infection rates, and particularly sexually transmitted infection rates, do not vary significantly between the clinics (Table 2). Pregnant women, however, differ significantly from their non-pregnant counterparts in this regard, with a higher rate of Candida infections and a surprisingly low rate of chlamydia infection.

\begin{tabular}{||l|c|c|c||}
\hline \multicolumn{4}{|c||}{ Table 2 } \\
\multicolumn{1}{||c|}{$\begin{array}{c}\text { Percentage of Women with Infection (by pathogen): } \\
\text { Comitán General Hospital Outpatient Sample }\end{array}$} \\
\hline \hline \multicolumn{1}{|c|}{ Pathogen } & $\begin{array}{c}\text { GMC Non-pregnant } \\
(\mathbf{n}=123)\end{array}$ & $\begin{array}{c}\text { GC Non-pregnant } \\
(\mathbf{n}=140)\end{array}$ & $\begin{array}{c}\text { Pregnant (both sites) } \\
(\mathbf{n}=153)\end{array}$ \\
\hline \hline Syphilis & 0 & 0 & 0 \\
\hline Gonorrhea & $2.5(\mathrm{n}=120)$ & 2.1 & 0 \\
\hline Trichomonas & 5.7 & 2.1 & 3.8 \\
\hline Candida & 15.4 & 21.4 & 33.1 \\
\hline Bacterial vaginosis & 28.5 & 27.1 & 25.5 \\
\hline Chlamydia & $15.6(\mathrm{n}=45)$ & $16.7(\mathrm{n}=60)$ & $2.5(\mathrm{n}=40)$ \\
\hline
\end{tabular}


In the periurban/ejido group ( $\mathrm{n}=201)$, only three women were pregnant, so analysis was not conducted separately by place of residence. One of the three pregnant women tested positive for chlamydia. The infection rates for this group are presented in Table 3.

Additional findings from the physical exam are also troubling. In the hospital sample, four cases of previously detected invasive cancer, and six cases of carcinoma in situ, were noted. In the community sample, two cases of carcinoma in situ were detected.

\begin{tabular}{||l|c|}
\hline \multicolumn{2}{|c|}{ Table 3 } \\
$\begin{array}{c}\text { Infection Rates Among Periurban } \\
\text { and Ejido Women }\end{array}$ \\
\hline \hline \multicolumn{1}{|c|}{ Pathogen } & Infection Rates \\
\hline \hline Syphilis & 0 \\
\hline Gonorrhea & 0 \\
\hline Trichomonas & $18 / 201=9 \%$ \\
\hline Candida & $12 / 201=5.8 \%$ \\
\hline Bacterial Vaginosis & $76 / 201=37.8 \%$ \\
\hline Chlamydia & $27 / 141=19.1 \%$ \\
\hline
\end{tabular}

In summary, the data collected indicate the following:

- Infection rates are high among these women (particularly for candida, bacterial vaginosis, and chlamydia)

- Cervical ulceration is common, and vaginal condyloma rates are high among the women in the community sample

- There is substantial unanimity of results between the two recruitment sites (hospital and community samples)

- Where it could be measured with sufficiently large numbers, pregnant women seem to have more candida infection and less chlamydia infection

- Chlamydia infection rates are much higher than predicted based on other developing country prevalence data and on the results of a study of a high-risk sample (commercial sex workers) in Mexico

- In general, women in the community sample had greater infection levels for each pathogen, despite the fact that they had similar socio-demographic characteristics 


\section{Eugenio Pacelli de Barreto Teles}

Federal University of Ceara

Department of Community Health

Fortaleza, Brazil

In our study, we examined 407 sexually active women who were attending the family planning clinic at the State University of Campinas to initiate use of a contraceptive method. The clinic is well known to be the only public facility in the city that provides intrauterine devices (IUDs), and is therefore heavily oriented toward IUD service delivery. To some extent, women probably self-select before attending this clinic, because they know that the clinic will not provide IUDs to women who are not in monogamous relationships.

All patients enrolled in the study were screened by clinical exam, history, and laboratory findings. Researchers used saline wet mount to diagnose bacterial vaginosis (BV), candida, and trichomoniasis; gram stain to diagnose gonorrhea, BV, candida, and trichomoniasis; Pap smear for human papilloma virus (HPV); culture for gonorrhea; and fluorescent test for chlamydia.

Prevalence rates are indicated in Table 1. The clinical and medical history was used to exclude women who were felt to be inappropriate candidates for IUD use based on the likelihood of sexually transmitted genital infection. If cultures later revealed that an IUD had been inserted inadvertently into a woman with a pre-existing infection, the woman was called as soon as the results were known, and treated. Some women returned to the clinic with symptoms of infection prior to hearing of the laboratory findings.

\begin{tabular}{||l|c|c|c||}
\multicolumn{4}{|c|}{ Reproductive Tract Infection Prevalence } \\
\hline \hline & $\begin{array}{c}\text { \% Prevalence } \\
\text { of infection } \\
\text { (all women) } \\
(\mathbf{n = 4 0 7 )}\end{array}$ & $\begin{array}{c}\text { \% Prevalence of } \\
\text { infection among IUD } \\
\text { acceptors } \\
(\mathbf{n = 3 2 7 )}\end{array}$ & $\begin{array}{c}\text { \% Prevalence of infection } \\
\text { among all non-IUD family } \\
\text { planning acceptors (n=80) }\end{array}$ \\
\hline \hline B. vaginosis & 25.8 & 25.1 & 28.8 \\
\hline Chlamydia & 6.7 & 5.9 & 10.0 \\
\hline Candida & 2.2 & 2.4 & 1.3 \\
\hline Trichomoniasis & 1.7 & 2.1 & 0.0 \\
\hline HPV & 1.0 & 1.2 & 0.0 \\
\hline Gonorrhea & 0.0 & 0.0 & 0.0 \\
\hline No infection & 64.1 & 66.0 & 62.0 \\
\hline \hline
\end{tabular}


When clinical and medical histories were compared to the laboratory results, the clinical predictors were found to be surprisingly inadequate. Of all the reproductive tract infections (RTIs) examined, clinical diagnosis of BV resulted in the fewest false positives by a large margin.

Overall, however, the efficacy of clinical diagnosis was unsatisfactory; the indicators tended to be of low sensitivity and to generate high proportions of false positives (see Table 2).

\begin{tabular}{||c||c|c|c|c||}
\hline \multicolumn{5}{|c||}{ Table 2 } \\
\multicolumn{1}{|c||}{ Accuracy of the Clinical Diagnosis of Genital Infections } \\
\hline \hline \multicolumn{1}{|c|}{ Infections } & Sensitivity & Specificity & False + & False - \\
\hline \hline Chlamydia & 7.4 & 92.8 & 93.1 & 6.7 \\
\hline Trichomoniasis & 42.9 & 96.5 & 82.4 & 1.0 \\
\hline Candida & 33.3 & 97.0 & 80.0 & 1.5 \\
\hline B. vaginosis & 41.0 & 90.7 & 39.4 & 18.5 \\
\hline \hline
\end{tabular}

The prevalence of genital infections among IUD acceptors was lower than among the acceptors of other methods, although this was not statistically significant. Out of the 327 IUD acceptors, 19 tested positive for chlamydia, two of whom developed clinical signs of pelvic inflammatory disease (PID). One of these women was treated with drugs, but retained her IUD; the other was treated with drugs and had the IUD removed.

We found that, despite relatively little "high risk" sexual behavior, new acceptors of contraception had a significant prevalence of chlamydial cervicitis and were not easy to identify through any means other than laboratory examination. This underscores the need for cheaper and simpler diagnostic tests, but also suggests a simultaneous need to explore alternative options for improving the safety of contraceptive service provision.

\section{Joan Kaufman}

Abt Associates, Inc.

Cambridge, Massachusetts

The study on which I will report was carried out in collaboration with Professor Yan Liqin and her colleagues at Kunming Medical College in Kunming, the capital of Yunnan province, China. We decided to conduct the study because previous research had found high rates of vaginitis and cervicitis in Yunnan, suggesting underdiagnosis of reproductive tract infections 
(RTIs). Yunnan, which is located in southwest China, borders Burma, Laos, and Vietnam.

Other studies and factors point to high RTI prevalence in China. I will discuss some of these briefly before moving on to our results of the study in Yunnan. In 1992, the Ford Foundation carried out a reproductive health survey of 8,500 women in China, which revealed high rates of self-reported vaginitis and vulval itching. National statistics indicate that more than 40 percent of women who use contraceptives, or 60-70 million women, use IUDs and abortion rates are high as well, providing an opportunity for iatrogenic infection at lower level clinical facilities, where many of these procedures are performed. Sexually transmitted disease (STD) rates are rising nationwide, and especially in urban areas. Within the last few years, sexual transmission of human immunodeficiency virus (HIV) has increased. China's tremendous population movements from the rural areas to the cities and migrant workers moving from city to city also influence HIV prevalence patterns. Yunnan, however, accounts for 80-90 percent of China's HIV, mainly concentrated among injected heroin users near the Burmese border.

The Yunnan study mandate was two-fold. We began by compiling and reviewing existing information on RTIs in China from a variety of sources. Although Ministry of Health officials often say there are no cases of pelvic inflammatory disease (PID) or STDs in the country, the incidence of STDs has been rising, as noted above and as many small, but unconnected, studies reveal. Our literature review compiled existing information on RTIs and STDs in China, and we tried to answer several questions, including: What has been done in China regarding RTIs and STDs? What services are available? Are RTI treatments standardized? How much do they cost?

We found that, as suspected, rates of cervicitis in China are high. In a variety of studies conducted in different areas of the country, rates of visually observed cervicitis were found to be $60-70$ percent. We also learned that there is little capacity to diagnose RTIs below the county level of service, while most people seek health services at the township level (Table 1). In addition, the treatment of symptoms varies widely. Some women are treated with traditional medicine, while others
Table 1

STDs For Which Different Hospitals/Health Centers Have Testing Capacity

\begin{tabular}{||c|r|r|r|r||}
\hline \multicolumn{5}{|c||}{ Table 1 } \\
\multicolumn{5}{|c||}{ STDs For Which Different Hospitals/Health } \\
Centers Have Testing Capacity & \\
\multicolumn{1}{||c|}{ Items } & Province & County & Township & Village \\
\hline \hline Trichomonas & $100 \%$ & 76.1 & -- & -- \\
\hline Candida & $100 \%$ & 76.1 & -- & -- \\
\hline Gonorrhea & $100 \%$ & 61.8 & -- & -- \\
\hline Syphilis & $100 \%$ & 47.1 & -- & -- \\
\hline Chlamydia & $100 \%$ & -- & -- & - \\
\hline
\end{tabular}


receive antibiotics. Laser therapy is used for more serious cervicitis, which is worrisome given the possible ill effects of this procedure. Our primary conclusion was that there is an urgent need to improve the clinical diagnosis of cervicitis and to determine its underlying etiology (for example, whether it is related to STDs or other RTIs).

Following the literature review, we carried out a field survey in two Yunnan counties, Chengjiang and Luliang, which are about 100 kilometers from Kunming. Our aims were to establish the prevalence of RTIs and examine health, socio-economic, and behavioral risk factors. Data were collected using a questionnaire on social and behavioral risk factors; conducting clinical exams for symptoms; and conducting lab tests for candida, trichomoniasis, bacterial vaginosis, gonorrhea, and chlamydia. Local field testing was followed by a "gold standard" test in Kunming, to confirm the presence of infection and assess lab capacity at the local and central levels.

Rates of cervicitis were

found to be alarmingly high, although rates of specific RTIs were lower (Table 2). In examining possible determinants, preliminary analysis of the data showed the following: most women have access to tap or well water (water purity is good in China); the frequency of bathing varies greatly (32 percent of women bathe once a week and 68 percent bathe less than once a week); the rate of IUD use (45 percent of current contraceptive users) is similar to the national level;

\begin{tabular}{|c|c|c|}
\hline \multicolumn{3}{|c|}{$\begin{array}{c}\text { Table } 2 \\
\begin{array}{c}\text { Preliminary Results: Findings from RTI Baseline Survey } \\
\text { in Chengjiang and Luliang ( } \mathrm{N}=\mathbf{2 0 2 0})\end{array} \\
\end{array}$} \\
\hline Diseases & Cases & Rate (\%) \\
\hline Normal women & 379 & 18.8 \\
\hline Cervicitis & 1176 & 58.2 \\
\hline Candida vaginitis & 786 & 38.9 \\
\hline Trichomonas vaginitis & 327 & 16.2 \\
\hline Bacterial vaginosis* & 175 & 14.7 \\
\hline Gonorrhea & 7 & 0.3 \\
\hline Chlamydia** & 90 & 5.5 \\
\hline \multicolumn{3}{|c|}{$\begin{array}{l}1189 \text { women were tested for bacterial vaginosis. } \\
1643 \text { women were tested for chlamydia. }\end{array}$} \\
\hline
\end{tabular}
21 percent of the women had had one abortion, while 8 percent had had more than one. Self-reported symptoms revealed disturbingly high levels of morbidity (37 percent reported itching, 35 percent reported abnormal discharge, and 53 percent reported malodorous discharge). Analysis of risk factors is continuing and the results should be available in mid-1996.

Our qualitative work was not as successful, due primarily to the difficulties of carrying out anthropological research in a country where social science research has been taboo for more than 30 years. We did succeed in eliciting some interesting information, however. The women 
surveyed call all RTIs "syphilis," and also have other terms for specific RTIs. Candida, for example, is referred to as "syphilis" or "lower body itching." If women use the latter term, they receive traditional herbal medication, which only works for a short time. They use graphic names for their infections, which are descriptive of the symptoms, including "nasal mucous" for discharge and "stool smell" for odor. Most women do not believe that RTIs are related to sex. Many believe that they are the result of poor hygiene and that they can be caused by an imbalance of hot and cold in the body.

\section{Conclusions}

We are working to convince the local health authorities to pay greater attention to RTIs. We hope that our study will help the Ministry of Health refine its definition of cervicitis and determine its causes, which is urgent given the high levels of cervicitis and the risk of HIV in Yunnan. We also hope to develop a risk assessment tool for specific RTIs, which could be used in Yunnan to help identify women at high risk in order to refer them for further screening before IUD insertion or abortion. Finally, we are also providing training to local health personnel on RTI diagnosis and treatment. 


\section{INDIVIDUAL PERCEPTIONS: QUALITATIVE RTI RESEARCH}

\section{Huda Zurayk}

The Population Council

Cairo, Egypt

The interdisciplinary research on which I will report focused on gynecological and related reproductive morbidity among women in Giza, a rural area outside of Cairo, Egypt. The study group was a community sample of 509 women; eligible participants were ever-married, nonpregnant women, aged 14-60. They were primarily non-literate and most were currently married; most had been younger than 16 years old when they first married, and had had more than three children.

Household interviews were conducted to collect background information on the women and their reported symptoms of morbidity. The women were invited to a health center for a clinical exam and laboratory tests. It was determined that 51 percent of the women had RTls, 22 percent had cervical ectopy, 11 percent had suspicious cervical cell changes, and 56 percent had genital prolapse (see Table 1). Based on these findings, it is clear that women's health problems extend beyond those related to pregnancy.

Our objective was not only to collect medical data on the prevalence of reproductive tract infections (RTIs) and related gynecological morbidity, but to

\begin{tabular}{|c|c|}
\hline $\begin{array}{c}\text { Table } 1 \\
\text { Percent Prevalence of Gynecologi }\end{array}$ & \\
\hline Condition & $\%$ \\
\hline $\begin{array}{l}\text { Reproductive tract infections }(\mathrm{RTIS})^{*} \\
\cdot \text { Vaginitis } \\
\cdot \text { Bacterial vaginosis }=22 \\
\cdot \text { Trichomonas }=18 \\
\cdot \text { Candida }=11 \\
\cdot \text { Cervicitis }(\text { Chlamydia }=9) \\
\cdot \text { Pelvic Inflammatory Disease }\end{array}$ & $\begin{array}{c}10 \\
2 \\
\end{array}$ \\
\hline Cervical ectopy & 22 \\
\hline Suspicious cervical cell changes & 11 \\
\hline $\begin{array}{l}\text { Genital prolapse: } \\
\text { Posterior or anterior vaginal } \\
\text { Posterior and anterior vaginal } \\
\text { Vaginal and uterine }\end{array}$ & $\begin{array}{c}56 \\
27 \\
21 \\
8\end{array}$ \\
\hline Number of women & 502 \\
\hline
\end{tabular}
compare those findings with women's perceptions and investigate health-seeking behaviors related to gynecological symptoms. We found that the majority of women do not use health services when they experience such symptoms, because they do not consider them to be abnormal or problematic. The only type of problem a substantial proportion of women perceive as problematic, and as cause for consulting a physician, is a delay in conception. On the other hand, medical consultation was least likely for 
problems with intercourse.

The women lack awareness of the potentially serious nature of certain RTIs. Socioeconomic and cultural constraints compound the problem of addressing RTIs: for example, when the study field workers tried to take the women found to suffer from a disease for health care, the women did not always have time to go; often field workers had to negotiate for permission from the husband or mother-in-law to do so. Related issues documented by the study include women's low position of power within the community, poor economic conditions, heavy workload, and low educational status. Case studies of the women referred for health care were prepared and published jointly by UNICEF and the Population Council in a book entitled The Silent Endurance. These qualitative texts complement the quantitative data on prevalence, and forcefully show the social conditions that constrain the health situation and health-seeking behavior of women. More research is needed on women's perceptions of their health within the context of their socioeconomic and cultural circumstances.

As a result of these findings, we decided to begin developing a health education packet that will raise the awareness of women about the symptoms of reproductive morbidity and of the need for care.

\section{Adepeju Olukoya}

Women's Health Association Lagos, Nigeria

Based on hospital data and the high level of infertility-as much as 50 percent in some communities-we know that reproductive tract infections (RTIs) are prevalent in Nigeria.

Intrauterine devices (IUDs) are one of the most popular means of contraception, a troubling fact in the context of Nigeria's resource constraints, serious electricity and water supply problems, and probable high infection rates.

The objectives of the RTI study we conducted were to:

- define men and women's perceptions of reproductive morbidity and, specifically, their perceptions of vaginal secretions, sensations, and sores, using a life-cycle approach;

- describe help-seeking behavior for perceived abnormalities; and

- define male and female perspectives with regard to the provision of RTI care and family planning services.

The study had two phases, the second of which was truncated due to political problems. The methodology used in Phase I consisted of in-depth interviews related to women's experience 
through the life cycle, including puberty, the reproductive years, and menopause. During this phase, we spoke with traditional healers, pregnant women, postpartum women, family planning users and non-users, herb sellers, and menopausal women.

In studying male and female perceptions of reproductive morbidity, we found that the range of normal to abnormal was very wide: vaginal itching, "hotness," and "tightness" for example, are considered normal phenomena at certain times during the female life cycle. Similarly, menopause is not seen to have a beginning or an end; if a post-menopausal woman has vaginal bleeding, for example, she would simply think she had not yet completed menopause, when in fact the bleeding could be a sign of a serious problem. We found that it is socially acceptable for men to network sexually when their wives are pregnant or postpartum, while retaining the privilege of returning to their wives for sexual relations. Interestingly, we found that men refer to RTIs and sexually transmitted diseases (STDs) as infections "caught from women." We also learned that family planning methods are perceived to be causally associated with abnormalities in the genital tract.

Most women said that they would talk to traditional healers as the first line of help if they felt they had a problem. Most of the methods that traditional healers use-herbal preparations (including their use as pessaries), drinks, and so forth —are either harmful or, at best, do nothing to heal the women of their illness. We were surprised to learn that the traditional healers considered foul-smelling or bloody discharge to be abnormal. Most of the women in the study thought of such discharge as normal at some phase of life.

Our conclusions were as follows:

- Given that it is acceptable for a man to "network" sexually and continue to have sexual relations with his wife, she and her unborn child are placed at increased risk of RTIs. As such, there are culturally sanctioned increased risks of infection to mothers and children.

- Widespread misinformation and inappropriate help-seeking behavior affects women from puberty through menopause. These misperceptions are not limited to women of poor economic and educational status; educated and economically-privileged women also believe that certain types of abnormal discharge and other RTI symptoms are normal.

- Most women with RTIs are asymptomatic.

- Current help-seeking behavior may actually increase the incidence of illness.

\section{Nandini Oomman}

Johns Hopkins University

School of Hygiene and Public Health

Baltimore, Maryland 
The qualitative and quantitative study on which I will report was entitled "Ethnomedical models of dhola pani in rural Rajasthani women." Dhola pani, the local term for white discharge, was chosen as the focus of the study because it was a complaint that women frequently made to health care providers in this community. An ethnomedical model is a model of the way in which people in a particular community conceptualize an illness with respect to its causes, symptoms, pathophysiology, and treatment.

The first phase of the study involved ethnographic research. We began by selecting women in the community whom we felt would be good informants about the problem of dhola pani. The objectives of the first phase were to:

- ask women how they conceptualized the problem;

- determine if an ethnomedical model existed;

- determine the appropriate terminology to use to ask women related questions; and - generate appropriate instruments for further research.

The second phase of the study involved a survey to collect information on demographic variables as well as on women's menstrual and obstetric histories.

The third phase involved clinical examinations. We used this approach because the facilities to conduct lab tests were not available. The purpose of the clinical phase was to compare reports that women gave regarding dhola pani with clinical findings related to infection.

Through our research, we found that women complained of other possible reproductive health problems in addition to discharge. They said that they had equally serious problems with continuous bleeding, which they called "feet walking," and various types of prolapse, which they referred to as "body coming out." There were also many different terms used for discharge, including "body is melting" and "bones melting" for white discharge, and "brown falls" and "maroon falls" for bloody discharge.

Using the study findings, we constructed a model based on the way women describe their problems. They believe that economic disadvantage results in worry, anger, lack of food, and too much work; these problems lead to physiological weakness, which in turn results in discharge. They believe that sterilization, intrauterine device (IUD) insertion, abortion, problems in childbirth, eating hot foods, and different sexual intercourse practices are all "opportunistic" factors which affect them in their already weakened, vulnerable condition, resulting in discharge. The women also associate several other physical problems with discharge, including backaches, leg aches, 
sore veins, dizziness and fainting, and panic and anxiety.

As noted above, women perceive the root cause of discharge as an economic one. They do not view it as a sign of infection and therefore do not seek care. They also believe that the problem would be solved if they had better nutrition. A few quotes from the surveys illustrate this thinking: "If there is food in the house, there is no weakness," "Dhola comes from the same place as menstrual blood, so when a woman is strong, then blood flows properly. When she is weak and doesn't have her daily food, then dhola falls, her bones melt." It is clear that their understanding of the problem is very different from the biomedical model.

When women experience discharge, they sometimes seek treatment from traditional healers. Most often, however, they employ such home remedies as use of water chestnut, which they feel has high nutritive value. We also learned that many women speak to no one about the problem of discharge, while some speak with their husbands, mothers-in-law, and friends.

\section{Conclusion}

Women report dhola pani as a symptom of a larger problem, but they think of its etiology very differently than it is conceptualized in the biomedical model. Our clinical work indicates that reproductive tract infections (RTIs) are present in this community, but women's perceptions of the problem are such that they do not think that curative or preventative means for dhola pani are available. Sex and health education will thus be key in helping them to accept the role of health care and to seek it when they face this problem. 


\title{
THE UTILITY OF ALGORITHMS AND RISK SCREENING
}

\author{
Earmporn Thongkrajai \\ Community Health Development Project \\ Department of Medicine and Surgical Nursing \\ Khon Kaen University \\ Khon Kaen, Thailand
}

Conventional sexually transmitted diseases (STDs) are a major public health problem: they represent 20 percent of medical consultations in some developing countries and are among the top five reasons for which medical advice is sought. ${ }^{2}$ In sub-Saharan Africa, they are thought to be responsible for 17 percent of productive life-years lost to disease. For women, in particular, STDs present a severe threat to health and well being —in addition to pain and discomfort, STDs may also cause long-term reproductive health problems, such as infertility and chronic pelvic pain. Sexually acquired infections may also lead to ectopic pregnancy and cervical cancer, which can lead to death.

The provision of services to asymptomatic women is an essential part of STD programs, both to prevent complications and sequelae, and to interrupt the transmission of infection.

Without such services, STDs cannot, by definition, be controlled. Even in countries with the best developed STD prevention and control programs, services tend to concentrate on the treatment of those who seek care because they have symptoms. Many women, however, will be asymptomatic, and thus undiagnosed, prior to the development of complications. Others are either unaware of the significance of symptoms or are reluctant to seek care for fear of stigmatization.

Maternal and child health and family planning $(\mathrm{MCH} / \mathrm{FP})$ programs are in a unique position to assist in reducing the spread of STDs and human immunodeficiency virus (HIV) (80 percent of women with HIV infection are of reproductive age). Not only do such programs employ the largest pool of health personnel, but they also have experience dealing with such interventions as counseling and the provision of contraception, which are closely related to the prevention of STDs, including HIV. If these programs played a more active role in primary prevention, by encouraging behavior change, and in secondary prevention, through effective case management, they would reach many women. In addition, some women obtain health services, either for their children or for themselves, only through $\mathrm{MCH} / \mathrm{FP}$ programs.

2 WHO/GPA. Provision of STD Services in Maternal and Child Health and Family Planning Setting, Background Paper No. 8, June, 1992. 
An essential element in testing the feasibility of integrating STD services into $\mathrm{MCH} / \mathrm{FP}$ programs is the choice of a method for diagnosis and case management for asymptomatic women and those who do not report symptoms. To address this, a study conducted in Thailand developed an algorithm for diagnosis and management of STDs among women attending family planning and antenatal clinics under the $\mathrm{MCH} / \mathrm{FP}$ program in the Chumpae district hospital in Khon Kaen province. The specific objectives of the study were to determine the prevalence of STDs and associated risk factors among women attending the clinics, and to validate a risk score for STD management among women who do not report symptoms.

\section{Study summary}

Women presenting to family planning and antenatal clinics in the Chumpae district hospital during a period of ten weeks were included in the study, along with some additional women from the Nampong district, which is similar to Chumpae. A total of 793 women were enrolled. Identical data collection procedures were followed-a physical examination, specimen collection and testing for STDs, and a screening interview. Data analysis of the pooled cases was conducted as a preliminary attempt to develop and validate the algorithm.

Focus groups Four focus groups were held among women aged 18-45 from villages served by the Chumpae district hospital. The objective was to explore and gather information on women's perceptions and beliefs regarding possible symptoms related to STDs. Of particular interest were their definitions of and the terms they used for vaginal discharge, itching, malodor, lower abdominal pain, difficulty with urination, and discomfort or tenderness around the cervix. Information was collected on their knowledge, attitudes, beliefs, sexual behavior, and preventive and curative behaviors. This information was then used to prepare the questionnaire for structured interviews, described below.

Interviews Each woman attending the MCH/FP clinic was interviewed by a health worker using a structured questionnaire. Information was collected on the following:

personal characteristics: age, education, occupation, marital status, place of residence number of induced abortions previous STD(s) perceived risk of STD risk factors for STDs: age at first intercourse, number of sexual partners in the last year, duration of relationship with current partner, duration of marriage, change of partner in last three months

husband or partner's age, occupation, education, residence, STD status, length of time away in past three months contraceptive use

current symptoms: dysuria, vulvo-vaginal itching, dyspareunia, lower abdominal pain, 
vaginal discharge, genital ulcers, skin rashes

Physical examination Vaginal, cervical, urine, and venous blood specimens were collected. On-site lab tests were performed for T. vaginalis, $C$. albicans, bacterial vaginosis, $N$. gonorrhea, C. trachomatis, and syphilis. A bimanual pelvic examination was also carried out. All women were examined for the following:

- skin, sole, and palm rashes

- vaginal discharge (type, color, odor)

- cervical discharge (after cleaning), and whether mucopus

- cervical dysplasia/ectropion (whether contact bleeding), cervicitis

- genital ulcers

- genital warts

- condyloma lata

- anal alterations (ulcers, rectorrhea warts)

Health education and treatment All participants received advice and information on HIV/AIDS, and were offered a supply of condoms at the initial visit. Infected patients were treated according to the regimen used at government STD clinics.

\section{Results and discussion}

Study results indicate that the prevalence of chlamydia is slightly over 3 percent-about half the rate expected based on earlier data-while the prevalence of syphilis and gonorrhea are under 1 percent (Table 1). Women whose husbands often worked away from home and who had not lived with their husbands during the past three months had significantly higher rates of chlamydia than women whose husbands were away less frequently or who had lived with them in the past three months (Table 2). Women who reported lower abdominal pain had significantly higher rates of

Table 1

Prevalence of STDs Among Women Aged 15-39 Years in Pooled Sample ( $N=793)$

\begin{tabular}{||l|c||}
\hline \multicolumn{1}{|||}{ STD } & Percent \\
\hline Positive syphilis serology ${ }^{*}$ & 0.6 \\
\hline Gonorrhea & 0.1 \\
\hline Chlamydia & 3.3 \\
\hline * RPR and TPHA tests both positive \\
\hline
\end{tabular}
chlamydia than women who did not report this problem. No relationship was found between chlamydia infection and reports of dysuria, vaginal discharge, and vaginal itching. A positive leukocyte esterase dipstick (LED) test, however, 
was found to be associated with the presence of chlamydia. More than twice as many women tested positive, rather than negative, for the infection.

A logit regression analysis was conducted to determine the association of chlamydia with each of the four risk factors identified-frequency of the husband working away from home, husband and wife living together during the previous three months, lower abdominal pain, and a positive LED test. The only factor that did not remain significantly associated with chlamydia prevalence was a positive LED test.

Table 2

Proportion of Women in Pooled Sample Infected and Uninfected with Chlamydia by Selected Characteristics

\begin{tabular}{|c|c|c|c|c|}
\hline \multirow{2}{*}{ Characteristic } & \multirow{2}{*}{$\begin{array}{c}\text { Infected } \\
\%\end{array}$} & \multirow{2}{*}{$\begin{array}{l}\text { Uninfected } \\
\quad \%\end{array}$} & \multicolumn{2}{|c|}{ Total } \\
\hline & & & $\%$ & $\mathbf{N}$ \\
\hline \multicolumn{5}{|l|}{ Age (in years) } \\
\hline $15-19$ & 2.2 & 97.8 & 100 & (93) \\
\hline $20-24$ & 4.9 & 95.1 & 100 & (245) \\
\hline $25-29$ & 3.1 & 96.9 & 100 & (225) \\
\hline $30-34$ & 2.3 & 97.7 & 100 & (128) \\
\hline $35-39$ & 2.0 & 98.0 & 100 & $(102)$ \\
\hline \multicolumn{5}{|l|}{ Number of abortions } \\
\hline None & 3.3 & 96.7 & 100 & (631) \\
\hline One or more & 2.6 & 97.4 & 100 & (158) \\
\hline \multicolumn{5}{|l|}{$\begin{array}{l}\text { Frequency of husband working away from home } \\
\text { (past year) }\end{array}$} \\
\hline Never away & 2.9 & 97.1 & 100 & (391) \\
\hline One to three times & 0.6 & 99.4 & 100 & (169) \\
\hline Most of the time & $6.3^{*}$ & 93.7 & 100 & (224) \\
\hline \multicolumn{5}{|l|}{ Husband and wife lived together in past 3 months } \\
\hline Yes & 2.8 & 97.2 & 100 & (641) \\
\hline No & $6.5^{*}$ & 2.8 & 100 & (107) \\
\hline \multicolumn{5}{|l|}{ Self-reported symptoms } \\
\hline \multicolumn{5}{|l|}{ Dysuria: } \\
\hline Yes & 5.9 & 94.1 & 100 & $(102)$ \\
\hline No & 2.9 & 97.1 & 100 & (687) \\
\hline \multicolumn{5}{|l|}{ Vaginal discharge: } \\
\hline Yes & 3.7 & 96.3 & 100 & $(27)$ \\
\hline No & 3.3 & 96.7 & 100 & (764) \\
\hline \multicolumn{5}{|l|}{ Vaginal itching: } \\
\hline Yes & 4.0 & 96.0 & 100 & $(26)$ \\
\hline No & 3.2 & 96.8 & 100 & $(765)$ \\
\hline
\end{tabular}




\begin{tabular}{||l|c|c|c|c||}
\hline $\begin{array}{l}\text { Lower abdominal pain: } \\
\text { Yes }\end{array}$ & $5.8^{*}$ & 94.2 & 100 & $(224)$ \\
No & 2.3 & 97.7 & 100 & $(567)$ \\
\hline LED test on urine & & & \\
High $(100 \mathrm{cell} / \mathrm{ml})$ & $5.6^{*}$ & 94.4 & 100 & $(214)$ \\
Moderate $(75 \mathrm{cell} / \mathrm{ml})$ & --- & -- & $(11)$ \\
Trace $(10-25 \mathrm{cell} / \mathrm{ml})$ & --- & -- & $(2)$ \\
Negative & 2.5 & 97.5 & 100 & $(558)$ \\
\hline \hline
\end{tabular}


This methodology enabled us to determine the number of true cases diagnosed by an algorithm based on the four risk factors (true positives), the number of women treated based on applying the algorithm (true plus false positives), its sensitivity (number of cases detected/total number of infected women), its specificity (number of negative women/total number of uninfected women), and its positive predictive value (the number of true positives diagnosed by the algorithm/number of women treated based on applying the algorithm).

The results of the application of the algorithm are presented in Table 4. Although the model has a sensitivity of 76 percent, its specificity is less than 50 percent, and its

positive predictive value is under 6 percent. The latter result is particularly important: in order to achieve 76 percent sensitivity, the proportion of the population over-treated by using this algorithm is greater than 90 percent. This level of over-treatment raises ethical questions-through treatment of uninfected individuals - and cost questions - in that it uses scarce resources unnecessarily. On the basis of these findings, it has been determined that the algorithm cannot be used for screening women for chlamydia in MCH/FP facilities in Thailand.

Several risk factors were identified that are significantly related to the prevalence of chlamydia. Their combined effect, however, was almost negligible, with $\mathrm{R}^{2}$ measured through multiple regression analysis at only 0.04 . (The $R^{2}$ measures the proportion variation in the data that can be explained by all the risk factors tested in the model. In this case, the model explains less than 4 percent of the variation in prevalence. In other words, they are unable to account for 96 percent of the variation in prevalence.) It is, therefore, unlikely that they would be sufficient, along with the other risk factors, to increase the positive predictive value of the algorithm to an acceptable level. It should be noted that, where the prevalence of STDs is higher than in the setting studied here, such screening tools may prove to be more useful.

\section{Conclusions}

The low level of STD prevalence raises questions regarding the practicality of using an 
algorithm to diagnose STDs among women attending MCH/FP facilities in the Thai context. Even if the screening tool had a sensitivity and a positive predictive value of 100 percent, it would only identify four cases out of each 100 attendees, which would not justify the time and effort involved in employing it. As an alternative, an intervention that integrates STD education, referral, and selfassessment of risk into $\mathrm{MCH} / \mathrm{FP}$ programs should be investigated. This could be accomplished through training programs for health promotion officers, who are clinic based, and village health volunteers, who are based in the community. Such a training program would consist of the following:

Training health promotion officers to improve their knowledge about STD/HIV prevention and their ability to communicate this knowledge, and informing women who attend clinics on where STD services can be obtained (referral).

- Training for village health volunteers to improve their knowledge about STD/HIV prevention and services and ways to communicate this knowledge during home visits and group meetings, and educating women on how to assess their own risk of STD/HIV, based on conventional risk factors and those identified in the study.

The intervention would also include the provision of information on STD/HIV prevention and location of STD services within the information, education, and communication (IEC) component of the MCH/FP program.

\section{DISCUSSANTS}

Huda Zurayk

The Population Council

Cairo, Egypt

When we began the Giza study on which I reported earlier, we were interested in women's reports related to the presence of reproductive tract infections (RTIs) or symptoms indicating their presence. We were not only attempting to determine whether or not algorithms were useful for screening, but also to determine the magnitude of the problem in the community. The study was conducted in a small community; because of its cost, it could not be replicated on a larger scale. One of the objectives of this study was to learn the extent to which women's reports of symptoms, compared to medical exams, could give us an estimate of the prevalence of gynecological conditions including RTIs. 
Our work involved the use of a number of methods. Seventy-seven percent of the women reported discharge, but only 13 percent of the women considered it "not their nature," that is, suspicious to the women. The women reported characteristics of the discharge they were experiencing in terms of color, odor, consistency, and accompanying itching. When these were analyzed, 63 percent of the women were considered to have medically suspicious discharge. By comparison,

\begin{tabular}{|c|c|}
\hline $\begin{array}{c}\text { Table 1 } \\
\text { Prevalence of Reproductive Tract Infections (R } \\
\text { Various Diagnostic Methods }\end{array}$ & sing \\
\hline & $\%$ \\
\hline Presence of discharge by clinical examination & 83 \\
\hline Medically diagnosed RTI (lab tests) & 51 \\
\hline $\begin{array}{l}\text { Women's report of discharge } \\
\text { Presence } \\
\text { Suspicious to woman } \\
\text { Suspicious medically } \\
\end{array}$ & $\begin{array}{l}77 \\
13 \\
63 \\
\end{array}$ \\
\hline $\begin{array}{l}\text { Diagnosis of RTI based on review by physician of: } \\
\text { Interview questionnaire } \\
\text { Clinical exam sheet and questionnaire }\end{array}$ & $\begin{array}{l}61 \\
70\end{array}$ \\
\hline
\end{tabular}
the examining physicians observed discharge in 83 percent of women. We also asked an independent team of three physicians to review the women's reported symptoms from the interview alone, and to review these reports in combination with the medical exam sheets. In the former case, they determined that 61 percent of the women had RTIs; in the latter case, the figure rose to 70 percent. In both cases, physicians overestimated the problem. However, as an estimate of magnitude of the problem of RTIs, all methods pointed to its gravity, except women's perceptions of the seriousness of the discharge. When we tried to examine the agreement for each woman's report of discharge with the physician observation, we found poor correlation between the woman's report and medical diagnosis. Women's reports of discharge were thus shown not to be predictive of the occurrence of RTI.

We then tried to determine whether these results might relate to the fact that the women did not know what to look for in terms of symptoms and/or to their behavior prior to having clinical exams. We had asked them to refrain from washing prior to going to the clinic so that if they had reported discharge the physician would be able to observe it. Despite our request, however, many probably did wash before the exam, which is common practice.

Do we give up asking about women's perceptions of their symptoms since we know they are not predictive medically? Can we, through surveys, get some idea of the conditions women have? It is important-from the point of view of learning about women's experiences - to determine whether women have discharge or other symptoms, and what they consider to be serious. These reports can be used as a community assessment of the magnitude of the problem and are indicative of the perceptions of women and their health-seeking behavior related to 
symptoms of RTIs.

\section{Inne Susanti}

University of Udayana

School of Medicine, Pathology Department

Denpasar, Bali, Indonesia

I plan to discuss the utility of algorithms and risk screening based on a study of reproductive tract infections (RTIs) in Bali. The objective of the study, which was cross-sectional in design, was to determine the prevalence and range of RTIs among women presenting at clinics for menstrual regulation and to develop a simple and inexpensive approach for RTI detection. The information we collected was similar to that described by Dr. Thongkrajai, and the same questions were asked about discharge and other symptoms. We also conducted speculum exams and laboratory tests, and took vaginal specimens (for a potassium hydroxide $(\mathrm{KOH})$ odor test, $\mathrm{pH}$ test, wet mount culture, and gram stain), blood samples (for syphilis and HIV tests), and cervical samples (for chlamydia testing, Pap smear, and swab test).

We tried to determine risk levels from the demographic information collected using the questionnaires and compared these with the clinical data, but they did not correspond. We found that the algorithms were not predictive. As such, it is essential that more thought and discussion be devoted to the use of algorithms for RTI management.

\section{Discussion}

Christopher Elias: We should move away from the term "algorithm" because the word means different things to different people. We need to discuss two different issues: case management, on the one hand, and case finding, on the other. There are different ways to conduct case finding. The best is to use expensive diagnostic tests in a rationed manner, perhaps with high-risk populations: this has been done in the U.S. and Australia by testing adolescents, because we know they are at greater risk of having infections and that the consequences are particularly serious for this group, indicating that it may be wisest to focus extremely scarce resources in this way. We need to determine if screening by other means, such as risk scoring, has any utility. At the same time, and most importantly, we need to invest in better 
and cheaper diagnostic technology.

Beverly Winikoff: We have to examine the fact that one of every two women who are determined by risk screening to have an RTI does not have an infection. What are the consequences for that woman of being labeled in this way? What are the risks to people of being labeled positive or negatively falsely, and to which of these risk are we most averse? What is the response to a positive diagnosis? In resource-constrained environments, are people being treated for infections they do not have? These and other important questions must be explored. 


\section{BUILDING THE COALITIONS NEEDED TO ADDRESS RTIS: SERVICE PROVIDERS, POLICYMAKERS, COMMUNITIES}

Nguyen Kim Cuc

Vietnam Women's Union

Hanoi, Vietnam

Vaginal and cervical problems are common in Vietnam and have serious implications for the health of women and their families, especially through their potential impact on fertility. The prevalence of reproductive tract infections (RTIs) among women of reproductive age in Vietnam is approximately 50 percent, and as high as 80 percent in some provinces. Vaginitis and cervical infection are extremely common, affecting about 90 percent of women of reproductive age.

In the past, Vietnamese women, and particularly those in rural areas, used traditional medicine for RTIs and rarely sought help from the formal health care system. In recent years, however, the latter system has been strengthened and many more women now utilize its services. Unfortunately, many women in remote rural areas lack access to the services that urban women enjoy. As a result, the Vietnam Women's Union has made women's health care a priority. We believe that "Health is wealth," and have organized medical check-ups and consultations for women, as well as family planning education campaigns. The Union, which works in collaboration with the Ministry of Health and a number of provincial health services, has also conducted surveys to determine the causes of RTIs and, based on these findings, is developing intervention strategies.

Survey findings reveal the following:

- poor knowledge of hygiene in general, and of menstrual and sexual hygiene in particular;

- lack of safe water and poor sanitation; and

- poor medical services, including unsafe intrauterine device (IUD) insertion, abortion, and menstrual regulation.

Based on the incidence of RTIs and their root causes, some of which are mentioned above, the Vietnam Women's Union realized that the problem could not be addressed effectively unless a strong coalition was built among a wide range of institutions, including the Ministry of Health, the Ministry of Labor-which is responsible for the water supply program - and the War Invalid and Social Affairs and Youth Union, which is responsible for education on sanitation. 
Through this coalition, which began work in 1992, we hope to succeed in our efforts to reduce the incidence of RTIs.

\section{Inne Susanti}

University of Udayana

School of Medicine, Pathology Department

Denpasar, Bali, Indonesia

About 70 percent of the women surveyed in the study I described earlier had experienced vaginal discharge; most of the women had also experienced itching and most did not realize that these could be symptoms of a problem. Many women think that vaginal discharge is caused by stress, certain foods, or poor hygiene. In addition, some women use oral and vaginal preparations that affect reproductive tract infections (RTIs), including vaginal tightening agents for sexual intercourse. Women reported that they were unsatisfied with the information they received from health care providers when they did inquire about their symptoms; indeed, many indicated that doctors and other providers told them that discharge was no cause for concern.

We learned from women and from discussions with doctors and midwives that information about RTIs is scarce. Health care providers reported that the reason they did not conduct clinical examinations to test for RTIs is that the women they treat are modest and do not want to be examined by male doctors. In addition, doctors said they were hesitant to discuss the possibility that a woman might have a sexually transmitted infection because they did not want to disrupt her family life. In most cases, therefore, no vaginal specimens are taken. Almost all of the midwives and doctors interviewed reported that they make a diagnosis on the basis of the symptoms that a woman describes. The most common diagnosis made on this basis is candida.

The problem of RTIs has never been so urgent. As such, it is more important than ever that we overcome the obstacles to dealing with the problem, collaborate, form coalitions, and disseminate information about the prevention and treatment of RTIs. Possible steps include providing more training and information to health care providers, increasing program and policy focus in this area, setting up mobile clinics for RTI screening, and establishing interdisciplinary coalitions to address and research RTIs.

\section{Nicola Jones}

The Ford Foundation 
Manila, Philippines

There are three questions we might ask regarding coalition building around reproductive tract infections (RTIs):

1. Why do we need coalitions?

2. What are the obstacles to coalition building?

3. How do we overcome these obstacles?

We need coalitions for a variety of important reasons. Participants in a recent HIV/AIDS and Development Awareness Seminar Workshop in the Philippines, for example, suggested that these include: opportunities to improve skills, coordination and support, facilitating referrals, maximizing existing resources, and a wide range of other factors.

\section{Why do we need coalitions?}

As we have discussed during this meeting, RTIs are rarely perceived to be a problemeven by those who suffer from them. Unlike AIDS, they are a "silent emergency." Coalitions can help place RTIs higher on the public health agenda. I believe that a multi-sectoral approach is essential in this regard: RTIs are not simply a medical problem-they also have social, cultural, moral, economic, and political implications.

My experience in supporting coalitions suggests that while it is helpful to have as wide a membership as possible, numbers do not guarantee success. For RTIs to gain public attention, members must be driven by their own interest in, commitment to, and preferably passion for the issue - and not commandeered as representatives of a particular agency. They must also have access to accurate, local information. Research coalitions, in the form of participatory and interdisciplinary research programs, have a crucial role to play in identifying the issues and mobilizing action. 
Donors-and particularly private donors-are in a very privileged position in the area of coalition building, and have much to gain from them. Coalitions maximize the use of limited resources, generate energy, and achieve an impact that would not be possible with individual partners.

\section{What are the obstacles to coalition building?}

For coalitions to work effectively, members must understand and respect the contributions of those who represent different organizations or perspectives and share

\section{Obstacles to Coalition Building}

Status and power of physicians and lawyers Misunderstandings between medical, biomedical, and social scientists

Uneasy relationship between NGOs and government agencies

Few NGOs are interested in health

Many feminist NGOs are in capital cities Provincial grassroots women are often not organized and not linked with urban feminist NGOs

Policymakers' negative attitudes

Decentralization of responsibility for many services to local governments, with commensurate central government loss of implementing power Religion and cultural values

common principles and goals. There are several factors that work against open and equal partnerships. Non-governmental organizations (NGOs), for example, are often wary of working with governments. Physicians and lawyers rarely feel challenged by others, particularly by poor women. Feminist organizations from capital cities do not have close ties with grassroots women's organizations, which are rarely well organized. Many policymakers are uncomfortable with issues related to sexuality and reproductive health. Conservative religious views often conflict with women-centered approaches to these issues.

\section{How do we overcome these obstacles?}

In order to overcome these and other obstacles, the Ford Foundation in the Philippines is developing partnerships around the issues of sexual and reproductive health. We encourage interdisciplinary and multi-sectoral programs to research and address RTIs, in order to bring activists from a wide variety of backgrounds together to work effectively on the issues surrounding RTIs. We support national and regional working groups, the establishment of an interagency advisory committee to the government's Commission on Population to help develop an agenda that is sensitive to reproductive health concerns, and the development of an interdisciplinary diploma and a Masters level health/social science program on gender, sexuality, and reproductive health to train new professionals in the field. We are still in our first phase of combat against RTIs, but we recognize that encouraging communication and interaction among the full range of partners will be essential to the development of a successful national RTI prevention and 
treatment program.

In order to develop appropriate responses to RTIs, we also need to involve women and men in research and action programs. By encouraging active partnerships among communities and NGOs, universities, modern and traditional practitioners, and government agencies, we should ensure that the expanding knowledge base is systematically linked to policy and program development.

An often neglected factor in building and sustaining coalitions is having fun. During the last afternoon of a recent conference, participants celebrated with parlor games, dancing, prayers, and community singing. This kind of social interaction is crucial to bringing and keeping people together to work toward a common cause. 


\section{IMPACT ASSESSMENT: WHAT CRITERIA DO WE USE TO DEMONSTRATE THE IMPORTANCE OF RTIS TO POLICYMAKERS?}

\section{Ana Langer}

The Population Council

Mexico City, Mexico

Currently, there is agreement among international agencies on the importance of addressing sexually transmitted diseases (STDs) in the developing world and on the need to integrate STD management with other reproductive health services. Theoretically, merging vertical programs and services—such as maternal and child health $(\mathrm{MCH})$, family planning, and STD services-should have a synergistic, positive effect on women's health. In spite of this increasing consensus, however, strong skepticism arises among public health policymakers, program managers, health care providers, and donors when it comes to investing resources in this area. The following questions arise, which I plan to address in turn. Is it really necessary to address STDs? Are STD control programs cost-effective? Can the impact of STD control activities be measured? Is it feasible to implement all the services necessary to ensure that an STD control program is effective?

\section{Is it really necessary to address STDs?}

It is not uncommon to hear that STDs do not deserve the attention that international agencies are encouraging. Two main arguments, which are not based on true and objective information, are usually made to support this view.

STD prevalence is low among the general population Unfortunately, data on STD prevalence among the general population is very scarce. Only approximate figures can be obtained, based on women attending general, prenatal, or family planning clinics (Brunham and Embree, 1992; Donoso, et al., 1984; Faundes and Tanaka, 1992; Alvarez, et al., 1992; Weström and Mardh, 1984). These studies have found rather high prevalence rates for chlamydia, trichomonas, and, in some contexts, gonorrhea. There are, however, almost no population-based studies or studies of women who do not use these services. This information is urgently needed to assess the public health importance of the problem and to develop control and treatment strategies adapted to each context, since the STD epidemiology varies from country to country.

STDs are not fatal There is sufficient evidence of the devastating effects of reproductive tract infections (RTIs) and STDs on women's and infants' health (Weström, 1980; Weström, et al., 1981; Franco, 1991; Reeves, et al., 1989; Wasserheit, 1990). Pelvic inflammatory disease (PID), infertility, ectopic pregnancy, cervical cancer, increased risk of acquiring HIV/AIDS, fetal wastage, 
low birthweight, and neonatal blindness are among these effects, and there are others.

Dissemination of information about the complications of these preventable and treatable diseases should be more aggressive. Evaluating health care providers' awareness of the importance of STDs and their consequences should also be made a priority.

\section{Are STD control programs cost-effective?}

Data on the economic burden of STDs in the developing world, as well as the resources available and needed for their prevention and control, are very scarce. Most of the few existing studies are simulations. The World Bank (1993) has suggested a strategy for measuring the cost-effectiveness of health interventions, through which different interventions are compared in terms of the cost of achieving one additional year of healthy life. Outcomes are measured using disability-adjusted life-years (DALYs), which are also used to estimate the burden of disease. The unit cost of an additional DALY is the measure of an intervention's cost-effectiveness; the lower the number, the greater the value for money offered by the intervention.

Among communicable, maternal, and perinatal illnesses, the World Bank ranks STDs, excluding AIDS, third in terms of women's disease burden. In the list of priority health interventions, STDs rank second, following pregnancy-related illnesses, and are categorized as diseases that can, to a large extent, be controlled using cost-effective interventions (less than $\$ 100$ per DALY saved). The importance of STDs in terms of their contribution to the disease burden and the availability of effective and inexpensive interventions led the World Bank to recommend STD-related interventions as a component of a minimum package of care.

The limitations of the World Bank strategy include the fact that cost-effectiveness estimates were not calculated separately for each STD and that obstacles related to work in the field were not considered. For instance, screening for chlamydia may be less cost-effective than for syphilis, and the ratio varies according to local prevalence. In addition, availability of drugs, equipment, laboratory facilities, and so forth, would also modify the cost-effectiveness in different contexts.

Only a small proportion of the thousands of STD-related interventions were analyzed using the methodology described above. Among them, interventions for preventing congenital syphilis have a favorable cost-effectiveness ratio. Because syphilis treatment is simple and affordable, screening and treatment during the prenatal period has been widely recommended. Other studies have found that eye prophylaxis at birth to prevent gonococcal ophthalmia neonatorum is much less expensive than treating the cases themselves (Laga, et al., 1989), even at maternal gonorrhea prevalence rates of less than 1 percent. These activities have a favorable 
cost-effectiveness ratio in both developed and developing countries (Stray-Pedersen, 1983). Effective interventions exist for other STDs, but the lack of simple, appropriate, rapid, and inexpensive diagnostics for use in the field render these measures much more difficult and expensive to implement. Consequently, when resources are limited, such interventions should be targeted specifically to high-prevalence groups in order to be cost-effective. Estimates suggest that if the prevalence of an STD is greater than 10 percent, treating everyone in the risk group may be more cost-effective than screening, especially when laboratory facilities are not available or are insufficient (Piot and Rowley, 1992).

Using a different methodology_cost per case averted—Shulz and colleagues (1992) compared the seriousness of the problems conventional STDs cause to infants to that of the infectious diseases currently addressed by international donor agencies (tetanus, polio, measles, and pertussis). The authors concluded that the problems caused by STDs are at least as serious as those caused by immunizable diseases, and the interventions to deal with them seem to be more cost-effective. Indeed, if benefits to women were included, this would improve the cost-effectiveness ratio of the interventions even further. This hypothesis, and the World Bank approach described above, need to be field-tested to increase the likelihood that they will influence decisionmaking.

Piot and Rowley (1992) contributed to highlighting the economic burden of STDs by reviewing the information available on the direct and indirect costs of the management of STDs and their sequelae in developing countries. The authors calculated the direct costs of different screening procedures and concluded that while clinical diagnosis is the least expensive and most rapid, it is also the least sensitive and specific. They also pointed out that no data on the costs of managing the complications and sequelae of STDs are available; however, these costs would certainly be higher than those of controlling the infections. Over and Piot (1991) estimated the indirect costs of STDs and the benefits of preventing them (using discounted healthy life-years) in an urban area in Africa with high STD prevalence. According to their calculations, preventing STDs results in considerable improvements in health. Their indirect cost calculations do not, however, encompass the impact of STDs on infant morbidity and mortality nor the social and economic consequences of STD-related morbidity or mortality. Finally, Piot and Rowley (1992) synthesized the scarce information available about the effectiveness and costs of STD interventions. They stressed that each case of STD prevented will also prevent additional cases. It is not, therefore, sufficient to compare the benefits of preventing a single case to the cost of the activities necessary to do so; the benefits to individuals other than those immediately affected must also be considered. Analyses of the cost-effectiveness of behavioral interventions for the 
prevention of STDs have not been carried out. Condom promotion activities, and especially social marketing as opposed to free distribution, seem, however, to be successful.

Experts in health economics generally agree on the need to generate more empirical evidence about the economic impact of STDs. This information is essential to combatting existing skepticism. Gross cost-effectiveness estimates may not be enough to convince program managers, public health decisionmakers, and providers that the interventions are worthwhile, given competing priorities for resources and the logistical difficulties associated with work in this area. While an efficacy study may show that an intervention can work, an effectiveness evaluation showing that it works outside of the research milieu and an efficiency study showing that it is worthwhile and feasible are essential prior to widespread introduction of the intervention (Ronald and Aral, 1992).

\section{Can the impact of STD control activities be measured?}

The main goal of any intervention is to ameliorate the health problem it intends to address. To demonstrate impact, and before an intervention can be considered for widespread implementation, a well-designed and methodologically sound evaluation is required. The validity of the scientific evidence for an intervention can be considered proven when it has shown positive effects following a prospective, randomized, controlled, and community-based study. This is a very high standard, extremely difficult to achieve (Ronald and Aral, 1992). Quasi-experimental designs are an acceptable alternative when comparability among experimental and control sites is adequate and all relevant variables that need to be controlled for in the analysis are measured; both conditions are necessary to ensure that such studies have sound internal validity. Scientific evidence of impact can be categorized as tentative when it comes from uncontrolled, non-randomized, and often retrospective_or "before and after"—studies. Most evaluations of STD interventions fall into this category. The positive effects of an intervention can only be considered as assumed when there is no scientific evidence, but experts in the field think of it as worthwhile (Ronald and Aral, 1992).

In addition to appropriate research design, demonstrating impact requires accurate identification of the outcomes to be measured. The development of a careful conceptual framework based on current scientific knowledge during the preparation phase of an evaluation usually helps in this regard. Two types of impact outcomes-intermediate and final-can be measured. The type chosen will depend on the nature of the intervention being evaluated. The following example will help clarify this concept. The effects of an intervention consisting of lectures and radio campaigns to promote the use of condoms, for instance, was estimated by 
measuring changes in the awareness of the condom as a method of AIDS and STD prevention (intermediate outcome) and by actual changes in overall condom use as a prophylactic measure (final outcome) (Vernon, et al., 1990). Impact outcomes, whether intermediate or final, must be consistent with the goals of the intervention under evaluation. The impact of an intervention consisting of screening, diagnosing, and treating gonococcal infection during pregnancy, for example, would be based on changes in three different outcomes: the incidence of prematurity, neonatal ophthalmia, and postpartum endometritis.

There are also both impact and process outcomes. For an intervention consisting of the establishment of STD control services in a family planning clinic, the impact outcomes could be the prevalence of certain infectious agents among clinic users or the frequency of PID after intrauterine device (IUD) insertion. Both should be lower after the intervention is established, or lower than among users of a similar clinic. If the resources needed to complete a prevalence study are not available, or if patient follow-up is too difficult, process outcomes, such as the inclusion of information, education, and communication (IEC) about STDs in the clinic's routine practice or the number of lab tests performed, could also be used to demonstrate changes attributable to the intervention.

After identifying the outcomes that will allow the effects of an intervention to be demonstrated, researchers must be sure they have all the elements they need to measure these effects correctly. They must also develop adequate instruments to collect data and train people to do so. Attention to these issues is crucial if valid results are to be obtained.

\section{Is it feasible to implement all the services necessary to ensure that an STD control program is effective?}

Finally, feasibility also generates skepticism, and the list of requirements for establishing a comprehensive STD control program makes this understandable. What must STD programs do in order to be effective? (Population Reports, 1993)

- Develop overall strategies based on health care resources and disease prevalence patterns

- Develop effective services in primary health clinics

- Train and equip STD service providers to diagnose and treat patients in one visit

. Ensure a reliable supply of condoms and drugs to treat STDs

- Make good STD counseling a high priority 
- Strengthen STD training in medical, nursing, midwifery, and other health professional schools

- Provide in-service training for primary health care providers

- Involve private practitioners-pharmacists, private doctors, midwives, and so forth

- Conduct mass media campaigns and in-clinic programs to encourage people to recognize STDs, seek treatment, and use condoms

- Conduct surveillance to identify the most prevalent STDs and drug resistance to STDs

- Set up syphilis screening programs in antenatal clinics

- Set up special programs for high-risk populations

- Make sure that the sexual partners of STD patients are treated

- Combine STD and AIDS programs

Women have a right to obtain the care they need for their health problems, and professionals, researchers, and activists working in the women's health field have a duty to help meet those needs. Skepticism is sometimes authentic, but it can also be an expression of awareness of the difficulties and severe constraints we face in the developing world. Research on STDs has not yet provided enough information to overcome the skepticism; given the significance of the problem and the magnitude of the obstacles to overcoming it, investment in such research is warranted. Each component of an STD program requires epidemiologic, health system, social, and economic research before it can be implemented with confidence. Demonstration projects to evaluate comprehensive programs involving most of the components listed above are also necessary.

\section{REFERENCES (Langer)}

Alvarez, M.E., L.I. Avendaño, F. Ramírez, R. Tinoco, K. Tolbert, and D. Halperin. 1992. "The Prevalence of Sexually Transmitted Diseases in the Outpatient Department of the Comitan Hospital, Comitan, Chiapas." Final report to The Population Council, Comitan Center for Health Research.

Brunham, R.C. and J. Embree. 1992. "Sexually Transmitted Diseases: Current and Future Dimensions of the Problem in the Third World." In Reproductive Tract Infections: Global Impact and Priorities for Women's Reproductive Health, A. Germain, K.K. Holmes, P. Piot, and J.N. Wasserheit, Eds. (New York: Plenum Press).

Donoso, E., E. Vera, P. Villaseca, et al. 1984. "Infección gonocóccica en el embarazo." Revista Chilena de Obstetricia y Ginecologia, 48:84-7. 
Faúndes, A. and A.C. Tanaka. 1992. "Reproductive Tract Infections in Brazil: Solutions in a Difficult Economic Climate." In Reproductive Tract Infections: Global Impact and Priorities for Women's Reproductive Health, A. Germain, K.K. Holmes, P. Piot, and J.N. Wasserheit, Eds. (New York: Plenum Press).

Franco, E.L. 1991. "Viral Etiology of Cervical Cancer: A Critique of the Evidence." Journal of Infectious Diseases, 13:1195-1206.

Laga, M., A. Meheus, and P. Piot. 1989. "Epidemiology and Control of Gonococcal Ophthalmia Neonatorum." Bulletin of the World Health Organization, 67:471-478.

Over, M. and P. Piot. 1991. "HIV Infection and Sexually Transmitted Diseases." In Disease Control Priorities in Developing Countries, D.T. Jamison and W.H. Mosley, Eds. (New York: Oxford University Press, for the World Bank).

Piot, P. and J. Rowley. 1992. "Economic Impact of Reproductive Tract Infections and Resources for their Control." In Reproductive Tract Infections: Global Impact and Priorities for Women's Reproductive Health, A. Germain, K.K. Holmes, P. Piot, and J.N. Wasserheit, Eds. (New York: Plenum Press).

Population Reports. 1993. Controlling Sexually Transmitted Diseases, Series L, No. 9.

Reeves, W.C., L.A. Brinton, M. García, et al. 1989. "Human Papilloma Virus Infection and Cervical Cancer in Latin America." New England Journal of Medicine, 320:1437-41.

Ronald, A. and S.O. Aral. 1992. "Assessment and Prioritization of Actions to Prevent and Control Reproductive Tract Infections in the Third World." In Reproductive Tract Infections: Global Impact and Priorities for Women's Reproductive Health, A. Germain, K.K. Holmes, P. Piot, and J.N. Wasserheit, Eds. (New York: Plenum Press).

Shulz, K.F., J.M. Schulte, and S.M. Berman. 1992. "Maternal Health and Child Survival: Opportunities to Protect Both Women and Children from the Adverse Consequences of Reproductive Tract Infections." In Reproductive Tract Infections: Global Impact and Priorities for Women's Reproductive Health, A. Germain, K.K. Holmes, P. Piot, and J.N. Wasserheit, Eds. (New York: Plenum Press).

Stray-Pedersen, B. 1983. "Economic Evaluation of Maternal Screening to Prevent Congenital Syphilis." Sexually Transmitted Diseases, 4:167-172.

Vernon, R., G. Ojeda, and R. Murad. 1990. "Incorporating AIDS Prevention Activities into a Family Planning Organization in Colombia." Studies in Family Planning, 21(6):335-343.

Wasserheit, J.N. 1990. "Reproductive Tract Infections." In Special Challenges in Third World Women's Health (New York: International Women's Health Coalition).

Weström, L. and P.A. Mardh. 1984. "Salpingitis." In Sexually Transmitted Diseases, K.K. Holmes, P.A. Mardh, P.F. Sparling, et al., Eds. (New York: McGraw Hill).

Weström, L., L.P.H. Bengtsson, and P.A. Mardh. 1981. "Incidence, Trends and Risks of Ectopic Pregnancy in a Population of Women." British Medical Journal, 282:15-18. 
Weström, L. 1980. "Incidence, Prevalence, and Trends of Acute Inflammatory Disease and its

Consequences in Industrialized Countries." American Journal of Obstetrics and Gynecology, 138:880-92.

World Bank. 1993. World Development Report 1993. Investing in Health. (New York: Oxford University Press).

\section{Valerie Hull}

The Population Council

Jakarta, Indonesia

How do those of us working primarily in research convince those who are skeptical to pay more attention and allocate more funds to the prevention and treatment of reproductive tract infections (RTIs)? Who are the skeptics? They are donors, politicians, and health and family planning program managers; these are key strategic groups, although there are skeptics in other groups as well-including service providers, some advocacy groups, and some researchers themselves, who all demand different levels of proof that RTIs are a serious problem with costeffective solutions.

\section{Donors}

Donors ask, "What is an RTI?" and "Why should we pay attention to RTIs when there are women dying in childbirth, or when population growth is undermining development?" It is our job to raise their awareness of the consequences of RTIs; link RTI interventions to their priority programs, including Safe Motherhood and HIV programs; look for specific opportunities to improve service delivery related to RTIs, for example including RTIs in a project to upgrade laboratories or develop training curricula; and collaborate with Women in Development programs that are already working to integrate gender issues into other program areas.

\section{Politicians}

Politicians say, "RTIs cannot happen in my country—we do not have these kinds of problems," "Our religion prohibits prostitution so we do not have RTIs/STDs," and "Those international statistics you cite are not relevant here." In order to convince politicians to pay attention and channel scarce resources to RTI prevention and treatment, we need to:

- be proactive, by providing them with relevant information from the local context;

- acknowledge limits of global statistics, but stress global commitments to reproductive health; 
- acknowledge and explain the links between RTIs and behavior, and explain that not all RTIs are sexually transmitted; and

- accentuate the positive, by giving politicians the good news about successful pilot projects.

\section{Family planning managers}

Family planning managers say, "My task is to bring down the birth rate-women's health is another department's responsibility." In order to convince them of the importance of RTIs to their own work, we need to provide them with evidence from studies that reveal that linking RTI services with family planning programs has no negative effect on contraceptive service provision. We need cost studies comparing stand-alone family planning services with various levels of integrated services. We should also emphasize the influence that RTIs have on safe delivery and use - and continuation of use —of contraceptives.

\section{Health program managers}

Health program managers say, "We are already doing this kind of work" or conversely "We cannot afford to do this kind of work." To meet these arguments, we must do the following:

- provide them with evidence of the costs and limitations of existing programs, such as single-purpose STD clinics;

- help them to improve the RTI prevention and treatment services that are in place; and

- again, provide them with good news related to pilot projects.

In order to convince the skeptics to focus on RTIs, we need to provide them with information on the consequences of underdiagnosed and untreated RTIs, and illustrate the possibilities for integrating RTI interventions with existing programs, tailoring our approach strategically to the range of skeptics who make up our audience.

\section{Joan Kaufman}

Abt Associates, Inc.

Cambridge, Massachusetts

I would like to make a few comments about ways to convince policymakers to pay attention to reproductive tract infections (RTIs). RTIs have been a problem for a very long time. There are early studies from India that suggest they were identified as a problem 10-15 years 
ago. A variety of studies, however, suggest that in many settings provider attitudes have impeded appropriate management of RTIs. Providers often consider vaginal discharge to be normal, and have not paid attention to abnormal discharge. RTIs have only gained the attention of policymakers because of the new focus on sexually transmitted diseases (STDs), which has stemmed from the AIDS epidemic. However, much of the attention has been focused on symptomatic STDs in high-risk populations. Little attention has been paid to RTIs in the general population of women; RTls are the neglected "half-sister" of STDs in men.

In order to change this situation, we must try to provide information on the consequences of untreated RTIs in ways that matter to policymakers. Unfortunately, some of the early work on RTIs was faulty in terms of its methodology and did not help in this regard. In my opinion, we need to document and convey the fact that RTIs cause significant morbidity if not diagnosed and treated early. This is difficult, however, because many women with RTIs do not seek care for related problems.

The obvious major consequence of RTIs—infertility—can result in social stigma and other negative social consequences. In Africa, infertile women are frequently abandoned by their husbands and then migrate to cities; they may resort to prostitution and, as a result, contribute to urban health problems. Placing infertility in a larger social context, and documenting its costs, may be of use in drawing policymakers' attention to the problem.

The adverse birth outcomes and impact on offspring that may result from RTIs, including pregnancy loss, premature births, and low birthweight infants, should also be pointed out to policymakers. These problems could be prevented, in part, through diagnosis and treatment of infection during antenatal care provision.

Underdiagnosed RTIs also play a role in human immunodeficiency virus (HIV) transmission. In addition, the incidence of human papilloma virus (HPV) is related to cervical cancer rates. These facts should also be conveyed to policymakers more effectively to underscore the importance of early intervention.

We also need to do a better job of documenting the indirect effects of morbidity related to RTIs, such as the effect of pelvic pain and other symptoms which negatively affect women's ability to work. This type of economic analysis is difficult, but can be very convincing to policymakers.

The main task ahead is to document, to whatever degree we can, the impact of RTIs on women in terms of measurable and self-perceived morbidity. If we succeed in doing so, policymakers may be convinced to allocate more funding to prevention, early screening, and treatment. 
Valerie Hull

\section{LESSONS LEARNED FROM RESEARCH ON RTIS: \\ SUMMARIZING THE OBSTACLES ENCOUNTERED}

The Population Council

Jakarta, Indonesia

This presentation discusses the main obstacles related to research, dissemination, programming, and policy change in the field of reproductive tract infections (RTIs), as well as possible priorities for our work and ways of overcoming the obstacles we face.

\section{General obstacles}

A range of general obstacles underlie all work related to $\mathrm{RTI}$ research, policy, and programming. There is an overall lack of awareness of the problem and a resistance to acknowledging and learning more about it. Misperceptions and moralistic denial are found at the individual, community, program, and political levels. Yesterday, for example, we heard that the Chinese government had claimed to have eradicated sexually transmitted diseases (STDs) in China; research in sensitive areas can be interpreted as defying both moral order and legitimate authority. Women's position in society represents an additional, overriding obstacle, and relates primarily to their limited negotiating power in all spheres-from sexual relations to client-provider interactions to the policymaking arena. Poor quality of care also underlies the more specific obstacles we face: poor provider attitudes, training, management, and systems are formidable obstacles to reform. Resource constraints and allocation limit the quantity and quality of services; in some areas, resources are simply not available, and in others, health in general, and women's health in particular, receive a disproportionately low share of available funds. The general lack of resources, particularly among women, is also an obstacle because as we have heard, poverty underlies many of the causes of RTIs.

\section{Developing research}

Obstacles related to developing research can be divided into several categories. Set-ting relevant local priorities is critical, but is often problematic due to a lack of dialogue with or direct input from community members and a lack of alliances between researchers and service providers. We have heard a great deal about the importance of getting feedback from and involving family planning and health service providers and professional associations in research so that they will feel a sense of ownership. Despite our efforts, there is also lack of dialogue between researchers and policymakers and between local and international research communities. 
The lack of an international coordinating agency hinders our efforts to set global priorities, although the World Health Organization (WHO) STD

Diagnostics Initiative and Human

Reproduction Programme (HRP) can play this role to some extent. The lack of local research coordination is problematic to all research, not only research that pertains to RTIs. Avoiding duplication and maximizing research efforts is rare, and sometimes reaches appalling levels, wasting the limited resources we have available. Unfortunately, overcoming this obstacle is probably a pipe dream; most researchers do not want to be "coordinated." In many settings, the capacity of researchers is limited, both in terms of their general background and their training in specific research techniques.

There are numerous examples of possible local and global priorities and research populations (see boxes), which demonstrates how difficult it can be to choose from among them. We are presented with many potentially valuable research ideas, but decisions among them must be made.

\section{Conducting research}

The capacity of researchers is also relevant to conducting research. We are calling, for example, for more qualitative research, and in many countries there is a strong cadre of trained survey researchers now trying to come to grips with these new approaches. It takes some extra training and reorientation to achieve rigorous qualitative research. Without this rigor, "qualitative research" is really journalism, and maybe not even good journalism. More women need to be involved in research and more researchers with the capacity to establish rapport with female participants must be involved in related efforts. Weak laboratory support facilities are an obstacle to conducting research in many settings. Respondent sensitivity is also said to be an obstacle by
. secondary research

. epidemiological studies

qualitative research

interventions

other Operations Research

. antibiotic prophylaxis for IUDs

. sexuality

- gender relations

. ethnomedicine

. health service utilization antibiotic resistance
- management guidelines

microbicides and female-controlled methods

- inexpensive diagnostics

vaccine research 
health department officials, interviewers, or university-educated local researchers, but does not always prove to be a problem. Often, when you gather women in a room in an atmosphere that is conducive to discussing these issues, they have a great deal to say. As such, we are faced with "gatekeeper reluctance"; that is, it is often the educated elite who are more sensitive than the respondents. Finally, there are the ethical issues. What is the effect on informants of gathering information on these issues? What are the ethics of research that does not have an intervention component?

\section{Interpreting research results}

The critical ability of researchers influences their capacity to interpret research results. So often we see research reports that are primarily descriptive, rather than analytical or actionoriented. This analytical capacity must be developed. Lack of familiarity with qualitative research, and especially the analysis of qualitative research, comes up again here. Even if researchers are able to conduct focus group discussions, for example, rigorous analysis of the results is often a problem. Finally, there are inherent problems of measurement in the area of RTI research, including the whole area of quality control of diagnostics and the proper conduct of impact studies, which can be difficult in any field.

\section{Disseminating research results}

The writing skills of researchers is an obstacle that hinders the effective dissemination of research results. Researchers often do not present results in a way that is tailored to particular audiences, especially policymakers. They often do not establish links with the media or write for popular publications. Women's magazines in Indonesia, for example, are crying out for articles on women's health. If researchers were able to provide locally relevant, well- written reports, the impact of research results would be enhanced. The lack of a reading culture, however, applies in some settings, including Indonesia. Making reports readable and interesting, and presenting results through audiovisual means may help combat this obstacle. One implication of a lack of research coordination that is also problematic is that research reports become part of the (sometimes permanently) 'fugitive literature.' Finally, there is the moral climate or censorship of research results, which operates on two levels. First, there is a certain degree of self-censorship among academics. In Indonesia, for example, researchers avoid sensitive research topics, or do not report findings that are critical of government programs. Second, there can be outright censorship by authorities of critical reports. 


\section{Developing and proposing interventions}

I have divided interventions into six areas: education, preventive efforts, detection, treatment, technical/biomedical, and programmatic.

The needs for education are enormous. We have only limited knowledge of local terms and perceptions related to RTIs, which presents an obstacle to developing effective interventions. There is also a lack of tested educational approaches, in terms of both message content and appropriate media. Lessons have been learned from other health promotion efforts and, perhaps, from approaches that are being tested in the HIV field, but we will nonetheless need to test approaches that are specific to RTIs. Due to a lack of basic sex and reproductive health education, women lack knowledge of their bodies. Messages related to RTIs may need to begin at a very basic level. Developing appropriate messages for client self-assessment of risk, a subject we discussed earlier, is also an obstacle insofar as, again, there is much we do not know about message content and delivery.

Obstacles to preventive efforts other than education relate to the pervasive bias against condoms and barrier methods, both by programs and the population, that prevails in many developing countries.

There are various obstacles to detection, or diagnosis, including a lack of standardized terminology and criteria. For example, almost every study that we have reviewed here uses a different list of RTIs. There is also a discouraging lack of correspondence between clinical and laboratory findings and intrinsic limits to client self-diagnosis. There are difficult issues surrounding the management of asymptomatic cases, which relate in large part to the problems inherent in the development and use of appropriate, sensitive, and reliable behavioral risk screening methods. The limitations of diagnostics technology come up again and again. There is an additional aspect to this problem, which has not come up prominently in this meeting, but which has arisen in our research: there is a certain pride and independence among clinicians, an attitude that they do not need to rely on technology, and that (true or not) they have become so experienced at recognizing signs and symptoms through clinical examination that it might be a retrograde step to become dependent on lab technology when the technology itself is so limited. Provider training, quality of care, and laboratory support present additional obstacles to effective diagnosis, as does strict quality control, which applies to all aspects of diagnosis.

Obstacles to RTI treatment include the relative effectiveness of targeting core transmitter groups versus mass interventions, involving issues of stigmatizing the core group versus the cost- 
effectiveness of this approach. Antibiotic abuse and resistance are factors in many of the countries in which we work, as is the lack of a reliable drug supply for poorer segments of the population. Providers also tend to resist partner notification and treatment; they are reluctant to get involved and feel that they are not trained in what needs to be done or in the necessary counseling approaches. Training providers in counseling skills is extremely important. Lack of confidentiality, which inhibits individuals from seeking treatment, is a problem in many developing country settings. In Indonesia, for example, there is free HIV testing at a main teaching hospital, but most people do not want to attend as they feel that everyone will know if they test positively for the virus.

In the technical/biomedical area there seems to be a lack of consensus on key issues, including risk screening; antibiotic prophylaxis for intrauterine device (IUD) insertion; and the role of hygiene and its relationship to RTIs. The development of low-cost diagnostics is also a key technical/ biomedical concern.

Finally, there are the programmatic obstacles. Programs are often set up vertically, and there is a lack of coordination both within and between agencies. If the family planning program is separate from the health department, this is even more problematic, as they often perceive themselves as having very different missions.

\section{Policy change}

Openness, a general obstacle in this field, is particularly relevant with regard to policy change. Communication is also important, whether between agencies or between government and non-governmental sectors and researchers and academics. Donor/international community equivocation may also be a continuing problem. Are our developing country colleagues still getting mixed signals from the international community and donors with regard to the importance of RTIs? In some countries, I think this continues to be the case. Finally, lack of research hinders policy change, bringing us full circle to the obstacles to the development and conduct of research presented above.

\section{Esther Muia}

The Population Council

Nairobi, Kenya

In conducting research on sexually transmitted diseases (STDs) in Kenya, we encountered many of the obstacles discussed above. The project aimed to strengthen STD/HIV 
management. In the past, there were special STD clinics in Kenya and people were reluctant to attend them due to the stigma involved. When they were required to bring their partners with them, they would sometimes pay a stranger the equivalent of 50 cents to accompany them instead. An additional problem related to the fact that many women did not have access to the clinics, regardless of their limitations, for financial or social reasons.

We attempted to find a way to improve services in this environment and, after much consideration, decided on an approach that would involve both communities and the clinics themselves.

The community approach involved a focus on special groups, including adolescents and prostitutes, who were given information on how to gain access to services and about the symptoms of STDs. We also trained peer counselors to work with these special groups.

The clinic approach involved training more health care workers, including private practitioners, and obtaining more supplies and drugs.

We developed and employed a syndromic approach to STD management because existing lab facilities were not sufficient to enable us to test all clients. In addition, we devised forms that aimed to reduce waiting time for partner diagnosis and treatment.

The main obstacles we faced related to personnel problems and lack of equipmentincluding gloves, syringes, and drugs. Staff turnover was high, as providers felt that the project was requiring them to do more than they were originally hired to do. We also lacked effective supervisors. The socio-cultural obstacles related to the stigma attached to having or seeking treatment for an STD remained problematic.

We had tried to involve policymakers from the start, but it became clear that some of them had no idea what was going on. Some simply came to meetings and asked questions, but did not seem to be interested in taking steps themselves. When we approached policymakers to help pay for drugs to continue the project, many were reluctant. Our success in involving policymakers, therefore, was uneven. As noted above, we need to find ways to strengthen the link between researchers and policymakers so that when a research project is completed the community will continue to receive improved services.

On a positive note, the procedures we developed are being adopted by the Ministry of Health. However, it will be a long time before they are implemented because the Ministry must secure funding for drugs. Perhaps if we had made stronger ties with policymakers from the start, they could now be implemented more quickly.

\section{Nandini Oomman}


Johns Hopkins University

School of Hygiene and Public Health

Baltimore, Maryland

I will present some of the obstacles we faced when we conducted our research on ethnomedical models of vaginal discharge in India, which I described in detail earlier. Qualitative and quantitative data collection was carried out in remote, desert villages in rural India, which posed three types of obstacles:

Logistics Getting from one remote village to another was quite difficult. Because the sites were so far away from each other, we had to live in villages for four days a week for four to five months in order to gather data and get to know the women. We also had to set up clinics in schools and could not transport specimens to a hospital or university laboratory in time to make diagnoses. As local staff were not available, an entire research team had to be transported to each site.

Socio-cultural issues Women's and men's knowledge of their bodies was quite limited, and people were suspicious of gynecological examinations. Because women view discharge as resulting from economic problems, they did not think that a physical examination could benefit them.

Ethics It was not clear to us how we could, in this kind of environment, design a study to determine reproductive tract infection (RTI) prevalence rates or recruit a random sample of women. In addition, the research itself would raise the public's consciousness in this area, before the data was used, and without any guarantee that related services would be provided. Because the gynecological exam did not necessarily lead to treatment in women who felt they had, but were found not to have, a problem, some women felt ignored or mistreated. Should such women be given placebos or gifts? 


\title{
DEFINING THE RANGE OF FUTURE RESEARCH PRIORITIES AND INTERVENTIONS
}

\author{
Earmporn Thongkrajai \\ Community Health Development Project \\ Department of Medical and Surgical Nursing \\ Khon Kaen University \\ Khon Kaen, Thailand
}

Following are some research priorities that have emerged during our discussions.

- Consensus has not yet been reached on the consequences and scope of reproductive tract infections (RTIs). Although much research has been done on these topics, more is needed.

- RTI services need to be integrated with other health care services, including maternal and child health $(\mathrm{MCH})$ programs, so that individuals who seek or need them do not feel stigmatized.

- We need to find ways to integrate RTI services with existing $\mathrm{MCH}$ and family planning (FP) services more smoothly. At present, such efforts often result in health care providers becoming overloaded and in high staff turnover.

- We need to develop interventions that take into account the fact that RTIs are not only a medical problem, by looking closely at women's perceptions of their experiences, including discharge or other symptoms that may not fit into our biomedical model. For many women, RTIs are simply symptoms they do not understand and rarely get a chance to talk about. We also need to examine and work on the attitudes of health care providers in this regard. When a woman seeks help for symptoms that the provider does not recognize, how does that make her feel? What are the consequences?

- We must study the cultural factors that prevent women from talking about RTI-related symptoms or seeking help, and develop interview techniques that use appropriate questions to elicit this information.

- We need to know, on a context-specific basis, the types of traditional medicine that are used by women when they experience such symptoms as discharge or pain during urination.

- We must pay continued attention to the gender and empowerment issues related to RTI care and prevention. In Thailand, for example, there are many cases of women who, after becoming informed about AIDS, ask their partners to use condoms and are then physically abused for making this request. We need to help such women find effective and safe ways to negotiate with their partners.

- We need to continue to invest in the development of female-controlled technology.

- We need to conduct more research on RTIs and their relationship to AIDS.

- We must find ways to prolong the lives and improve the quality of life for those who are terminally ill with AIDS. In Thailand, for example, we use meditation and some 
traditional herbal medicine to improve the quality of life for women with AIDS.

\section{Adepeju Olukoya}

Women's Health Organization of Nigeria

Lagos, Nigeria

We need more research on social science topics, including:

- gender and power relations and the decisionmaking that occurs "behind closed doors" related to sexually transmitted diseases (STDs) and related protective measures;

- client acceptance of and attitude towards various types of service integration (family planning and RTI services, for example);

- health workers' perceptions of RTIs; and

- the relationship between personal hygiene and infection, including menstrual management and other practices that affect the genital tract.

There is an urgent need for biomedical research on topics related to reproductive tract infections (RTIs), including:

- appropriate low-cost diagnostics and screening; and

- appropriate screening tools.

Research on other interventions is also needed, including:

- community education;

- broadly defined case management; and

- training of health care workers, including "unorthodox" peer counselors and traditional birth attendants (TBAs). 


\title{
CLOSING SUMMARY
}

\author{
Beverly Winikoff and Christopher Elias \\ The Population Council \\ New York, New York
}

In closing, we will review the group's responses to the informal questionnaire (see Appendix), which will, perhaps, articulate where we stand as a group in terms of our thinking on reproductive tract infections (RTIs).

\section{Importance of RTIs/STDs}

There is a good deal of agreement that candida, bacterial vaginosis, and trichomonas are the most widespread infections, that they are relatively easy to deal with, and that they are not the most serious. This is a perfect case study for education and debate on public health issues. What do you do when the infections that are easiest to treat pose the least serious health problems? The group agreed that gonorrhea, chlamydia, syphilis, and human papilloma virus (HPV) are more serious infections, but more expensive to diagnose and treat, and more difficult to manage. Among these infections, syphilis and gonorrhea are the easiest to treat. There seems to be a great deal of frustration about our inability to provide appropriate services. Few participants talked about human immunodeficiency virus (HIV). Many focused on chlamydia, and many on low-cost diagnostics.

\section{Imagine you are a provider of IUD services. What STD/RTI services must you provide in order to offer contraceptive services of an acceptable quality?}

Thirteen participants responded that providers must be able to diagnose and treat RTIs in order to provide contraceptive services of an acceptable quality. Four of these participants stated that providers must be able to treat all RTIs. Ten respondents felt that providers must, at a minimum, be able to treat gonorrhea $(\mathrm{GC})$ and chlamydia, and some of these respondents also stated that providers must also be able to diagnose and treat pelvic inflammatory disease (PID), bacterial vaginosis, and "common RTIs" in order to provide quality services. Six participants stated that providers must provide risk screening by history or behavioral criteria, clinical selection, or self-screening. Information, education, and communication (IEC), pelvic exams, Pap smears, and other "check-ups" were cited by one participant each. An additional participant included a physical exam and cervical gram stain, and another indicated that the promotion of condom use 
for clients with more than one partner was necessary.

If you were providing family planning, but not the intrauterine device (IUD), would your answer be different from the one given to the question above?

Seven participants responded in the affirmative and stated that fewer RTI-related services would be needed to provide quality contraceptive services if the IUD were not offered. Five participants said their answer would not change, and asserted that RTI diagnostic capacity must be available in either case. Five participants said that the same level of service should be provided regardless of whether or not the IUD was offered, but noted that providers should only be responsible for performing clinical risk assessment if it was not. One participant said that more services were needed if the IUD was not provided, including HPV, syphilis, and candida screening, and another noted that the answer to this question would depend, presumably on other factors related to RTI prevalence, and so forth.

\section{Which is the most important RTI problem to be addressed?}

Most participants felt that chlamydia should be given priority. Three participants said that the development of low-cost diagnostic techniques was most important, and two that enhancing awareness of RTIs, and IEC efforts, were most important. Septic abortion was the fourth most commonly mentioned priority problem. Training, problems related to vaginal discharge, sexual decisionmaking issues, syphilis, acceptable means of prevention, and PID were cited as the most important problem by one participant each.

\section{If you were torn when answering the above question and want to mention another} important problem, what would it be?

Three participants cited issues related to HPV and cervical cancer, two cited gonorrhea, and prolapse, candida, PID, HIV, and low-cost diagnostics were cited by one participant each. One participant raised a more conceptual problem: can we rely on risk assessment?

\section{Which is the most important service to provide?}

Six participants stated that RTI diagnosis and treatment is the most important service, four cited counseling and information, three cited "screening" (although it is unclear whether this meant case finding or risk assessment), two cited primary prevention, and the empowerment of women and syphilis control were cited by one participant each. 


\section{Which is the second most important service to provide?}

Treatment, Pap smears, prenatal syphilis screening, development of laboratory capacity, education, safe abortion, and screening were among the responses to this question.

Our discussions over the last two days have been lively, and we have heard a great deal that has made us reevaluate our thinking related to RTIs. We have had the opportunity to talk about a very complex set of issues with a variety of people from diverse organizations. More questions have been raised than conclusions reached. Hopefully, we will be able to move forward in our efforts to answer these questions, which include:

1. How do we use the tools and information from the quantitative and qualitative research that has been conducted in both advocacy and program planning?

2. What do the results to date suggest about the approaches to service delivery that will be most fruitful?

3. How should we modify the direction and/or type of research that we are conducting on this topic?

Your continuing input on the third question will be of great use to us. Our impression is that the Population Council's Robert H. Ebert Program needs to build on, and move beyond, its work in this area: we have tended to focus on primarily descriptive studies and should move toward intervention studies that are more directly involved with service provision. Other research priorities include: examining health-seeking behavior related to RTIs; exploring ethnomedical models of the way providers diagnose infections; and standardizing diagnostic procedures. 
APPENDIX

Questionnaire

\begin{tabular}{|c|c|c|c|c|c|c|}
\hline Infection & Prevalence & Dx. Easy & Dx. Cheap & Rx. Easy & Rx. Cheap & Serious \\
\hline Candida & & & & & & \\
\hline B.V. & & & & & & \\
\hline Trichomonas & & & & & & \\
\hline Gonorrhea & & & & & & \\
\hline Chlamydia & & & & & & \\
\hline Syphilis & & & & & & \\
\hline HPV & & & & & & \\
\hline
\end{tabular}

1. Using a scale from + for "a little" to ++++ for "a great deal," please rate each of these infections according to the 6 characteristics above.

2.Imagine that you are a provider of IUD services. What STD/RTI services do you need to provide in order to offer contraceptive services of acceptable quality?

3.Would your answer to \#2, above, be different if you provided contraceptive services, but not the IUD?

4A. Which is the most important RTI problem to address? (Name one only)

B. Which is the most important RTI service to offer? (Name one only)

5.If you had trouble naming only one problem or service, above, here is your chance to name another. (Complete only if you felt torn between choice.)
A. Another problem:
B. Another service: 


\section{PARTICIPANT LIST}

Susan Allen

CONRAD Program

1611 North Kent Street, Suite 806

Arlington, VA 22209

Tel: (703) 524-4744

Fax: (703) 524-4770

Salwa an-Najjab al-Khatib

Union of Palestinian Medical Relief

Committees

P.O. Box 25047

Jerusalem, Israel

Tel: 972-2-834021

Fax: 972-2-829534/830674

Radhika Balakrishnan

Asia Programs

The Ford Foundation

320 East 43rd Street

New York, NY 10017

Tel: 212-573-5000

Fax: (212) 697-7354

Vilma Barahona

Department of Clinical Pathology

Hospital General Aurelio Valdivieso

Constitucion 301

68000 Oaxaca, Mexico

Fax: 52-951-46927

52-951-53181

Karen Beattie

AVSC International

79 Madison Avenue

New York, NY 10016

Tel: (212) 561-8000

Fax: (212) 779-9439

Martha Brady

The Population Council

One Dag Hammarskjold Plaza

New York, NY 10017

Tel: (212) 339-0618

Fax: 212-755-6052
George Brown

The Population Council

One Dag Hammarskjold Plaza

New York, NY 10017

Tel: (212) 339-0600

Fax: 212-755-6052

Judith Bruce

The Population Council

One Dag Hammarskjold Plaza

New York, NY 10017

Tel: (212) 339-0641

Fax: 212-755-6052

Christine Burillo

Center for Biomedical Research

1230 York Avenue

New York, NY 10021

Tel.: (212) 327-8746

Fax: (212) 327-7678

Jeanine Buzy

Division of HIV/AIDS, Office of Health

Bureau of Research and Development Agency for International Development Washington, D.C. 20523-1817

Tel: (703) 875-4402

Fax: (703) 875-4413

Davy Chikamata

The Population Council

P.O. Box 17643

Nairobi, Kenya

Tel: 011-254-2-713480

Fax: 011-254-2-713479

Christa Coggins

The Population Council

One Dag Hammarskjold Plaza

New York, NY 10017

Tel: (212) 339-0617

Fax: 212-755-6052 
Nguyen Kim Cuc

International Relations Department

Vietnam Women's Union

39 Hang Chuoi Street

Hanoi, Vietnam

Fax: 84-2-53143

Juan Diaz

The Population Council

Caixa Postal 6181

13081 Campinas

Sao Paulo, Brazil

Tel: 011-55-192-392856

Fax: 011-55-192-392856

Lena Ekroth

Swedish International Development

Authority

Birger Jarlsgatan 61

S 10525 Stockholm, Sweden

Fax: 46-8-612-6380

Christopher Elias

The Population Council

P.O. Box 11-1213

Nana Post Office

Bangkok 10112, Thailand

Tel: 011-66-2-251-4766

Fax: 011-66-2-255-5513

Kjell Enge

The Population Council-INOPAL

Office location:

Boulevard Liberacion 15-86 Zona 13

Edificio Obelisco, Oficina 305

Guatemala City, Guatemala 01013

Mail address:

Gua 107, P.O. Box 025368

Miami, FL 33102-5368

Tel: (011) 502-2-32-28-80

Fax: (011) 502-2-34-55-86

Anne Liv Evensen

Health Division

Norwegian Agency for Development

Cooperation (NORAD)

P.O. Box 8034

0030 Oslo, Norway
Tel: 011-47-22-31-44-00

Fax: 011-47-22-31-44-01

Anibal Faundes

The Population Council

Caixa Postal 6181

13081 Campinas

Sao Paulo, Brazil

Tel: 011-55-192-392856

Fax: 011-55-192-392856

Andy Fisher

The Population Council

One Dag Hammarskjold Plaza

New York, NY 10017

Tel: (212) 339-0603

Fax: 212-755-6052

Laurie Fox

Family Health International

P. O. Box 13950

Research Triangle Park, NC 27709

Tel: (919) 544-7040

Fax: (919) 544-7261

Geeta Rao Gupta

International Center for Research on Women

1717 Massachusetts Ave., NW, Suite 302

Washington, DC 20036

Tel: (202) 797-0007

Fax: (202) 797-0020

David Halperin

COMITAN

Hospital General de Comitán

SSA Chiapas

9a Calle Sur Oriente \#11

Comitán, Chiapas 30000

Mexico

Fax: 52-963-21861

Judith Helzner

International Planned Parenthood

Federation/Western Hemisphere

902 Broadway, 10th floor 
New York, NY 10010

Tel: (212) 995-8800

Fax: 212-995-8853

Douglas Huber

Pathfinder International

9 Galen Street, Suite 217

Watertown, MA 02172-4501

Tel: (617) 924-7200

Fax: (617) 924-3833

Jane Hughes

Population Sciences

The Rockefeller Foundation

420 5th Avenue

New York, New York 10018

Tel: (212) 869-8500

Fax: (212) 764-3468

Valerie Hull

The Population Council

TIFA Building, Suite 404

Jl. Kuningan Barat No. 26

Jakarta, Indonesia

Tel: (011) 62-21-5200094/5200494

Fax: (011) 62-21-5200232

Anrudh Jain

The Population Council

One Dag Hammarskjold Plaza

New York, NY 10017

Tel: (212) 339-0639

Fax: 212-755-6052

Nicola Jones

c/o The Ford Foundation

Manila--The Philippines

320 East 43rd Street

New York, NY 10017

Tel: (212) 573-5000

Fax: 212-697-7354

Louise Kantrow

The Population Council

One Dag Hammarskjold Plaza

New York, NY 10017

Tel: (212) 339-0632

Fax: 212-755-6052

Joan Kaufman
Abt Associates, Inc. 55 Wheeler Street

Cambridge, MA 02138

Tel: (617) 349-2645

Fax: 617-349-2610

Monica Knorr

The Population Council

One Dag Hammarskjold Plaza

New York, NY 10017

Tel: (212) 339-0535

Fax: 212-755-6052

Anu Kumar

Population Program

The MacArthur Foundation

140 South Dearborn

Chicago, IL 60603

Tel: (312) 726-8000

Fax: (312) 917-0334

Ana Langer

The Population Council

Apartado Postal 105-152

11560 Mexico, D.F., Mexico

(011) 52-2-280-1725/1475/1600

Fax: 011-52-5-281-0702

Ann Leonard

The Population Council

One Dag Hammarskjold Plaza

New York, NY 10017

Tel: (212) 339-0606

Fax: 212-755-6052

Robin Maguire

Center for Biomedical Research 
1230 York Avenue

New York, NY 10021

Tel.: (212) 327-8746

Fax: (212) 327-7678

Carolyn Makinson

The Andrew W. Mellon Foundation

140 East 62nd Street

New York, NY 10021

Tel: (212) 838-8400

Fax: (212) 223-2778

Judy Manning

U.S. Agency for International

Development

Office of Population

G/R\&D/POP, Room 811, SA-18

Washington, D.C. 20523-1817

Tel: (703) 875-4402

Fax: (703) 875-4413

William M. McCormack

Downstate Medical Center

Box 56

450 Clarkson Avenue

Brooklyn, NY 11203

Tel: (718) 270-1432

Fax: (718) 270-4123

Diana Measham

Consultant

1211 Alabama Avenue

Durham, NC 27705

Tel: (919) 416-9445 (w)

Fax: 919-416-0851

e-mail DMEASHAM@NANDO.NET

David Mercer

Program for Appropriate Technology in

Health (PATH)

4 Nickerson Street

Seattle, Washington 98109-1699

Tel: (206) 285-3500

FAX: 206-285-6619

Esther Muia

The Population Council

P.O. Box 17643

Nairobi, Kenya
Tel: 011-254-2-713480

Fax: 011-254-2-713479

Penda N'Diaye

The Population Council

01 BP 6250

Zone residentielle du bois, villa 558

Ouagadougou, Burkina Faso

Tel./Fax: (011) 266-33-57-95

Maggwa Ndugga

The Population Council

P.O. Box 17643

Nairobi, Kenya

Tel: 011-254-2-713480

Fax: 011-254-2-713479

Adepeju Olukoya

Women's Health Organization of Nigeria

1, Ikorodu Road 
P.M.B. 21178, Ikeja

Lagos, Nigeria

Tel: 234-1-962463, 493737

Fax: 234-1-524088, 4937937, 4960811

Nandini Oomman

Johns Hopkins University

School of Hygiene and Public Health

$615 \mathrm{~N}$. Wolfe Street

Room 2041 Stebbins

Baltimore, MD 21205

Tel: (410) 955-2786

Fax: (202) 364-4647

Rachel Pearce-Pratt

Center for Biomedical Research

1230 York Avenue

New York, NY 10021

Tel: (212) 327-8746

Fax: (212) 327-7678

Amy Pollack

AVSC International

79 Madison Avenue

New York, NY 10016

Tel: (212) 561-8000

Fax: (212) 779-9439

Willa Pressman

Office of Population

G/R\&D/POP, Room 811, SA-18

U.S. Agency for International

Development (USAID)

Washington, D.C. 20523-1817

Tel: (703) 875-4402

Fax: (703) 875-4413

Nancy Sloan

The Population Council

One Dag Hammarskjold Plaza

New York, NY 10017

Tel: (212) 339-0601

Fax: 212-755-6052

Inne Susanti

Jalan Kartini 105

Denpasar

Bali 80111, Indonesia

Tel: 62-361-224110/263690

Fax: 62-361-236021/225269
Eugenio Pacelli de Barreto Teles

Rua Coronel Byblos

60175-320 - Aldeota

Fortaleza, CE, Brazil

Tel: (085) 281-9000 ext. 2266

Fax: 085-281-2886

Earmporn Thongkrajai

Community Health Development Project (CHDP)

Department of Medical and Surgical Nursing

Faculty of Nursing

Khon Kaen University

Khon Kaen 40002, Thailand

Tel: (043) 424557

TLX: UNIKHON TH 55303 
Kathryn Tolbert

The Population Council

Apartado Postal 105-152

11560 Mexico, D.F., Mexico

Tel: (011) 52-2-280-1725/1475/1600

Fax: 011-52-5-281-0702

Sandra Waldman

The Population Council

One Dag Hammarskjold Plaza

New York, NY 10017

Tel: (212) 339-0525

Fax: 212-755-6052

Ellen Weiss

International Center for Research on

Women

1717 Massachusetts Ave., NW

Suite 302

Washington, DC 20036

Tel: (202) 797-0007

fax: (202) 797-0020

Beverly Winikoff

The Population Council

One Dag Hammarskjold Plaza

New York, NY 10017

Tel: (212) 339-0623

Fax: 212-755-6052

Susan Wood

International Women's Health Coalition

24 East 21st Street, 5th floor

New York, NY 10010

Tel: (212) 979-8500

Fax: (212) 979-9009

Vanaja Zacharapoulos

Center for Biomedical Research

1230 York Avenue

New York, NY 10021

Tel.: (212) 327-8746

Fax: (212) 327-7678

Inese Zalitis

Swedish International Development

Authority

Birger Jarlsgatan 61

S 10525 Stockholm

Sweden

Fax: 46-8-612-6380
Huda Zurayk

The Population Council

P.O. Box 115

Dokki, Cairo

Egypt

Tel: 011-202-573-8277

Fax: 011-202-570-1804 